\title{
Role of fiber inclusion in adobe masonry construction
}

\author{
Innocent Kafodya $^{\text {ab* }}$, F Okonta ${ }^{\mathrm{a}}$, Panos Kloukinas ${ }^{\mathrm{c}}$ \\ ${ }^{a}$ Civil Engineering Science Department, University of Johannesburg, South Africa \\ P.O Box 524, Auckland Park, 2006, South Africa \\ ${ }^{\mathrm{b}}$ Department of Civil Engineering, University of Malawi, The Polytechnic, Malawi \\ ${ }^{\mathrm{c}}$ Faculty of Engineering and Science, University of Greenwich, United Kingdom; Department of \\ Civil Engineering, University of Bristol, United Kingdom
}

\begin{abstract}
Adobe masonry construction constitutes a notable portion of the buildings in both urban and rural areas in less developed countries. Seismic performance of adobe buildings is poor, and lowcost retrofitting measures are required to enhance the resilience of such buildings during an earthquake. In this study, mechanical properties of fiber reinforced and unreinforced adobe masonry were investigated. Sisal fibers with length of $25 \mathrm{~mm}$ were used as reinforcing elements for mortar and adobe bricks at a fiber content of $0.75 \%$. A series of laboratory tests were performed on masonry triplets, couplets and prisms to determine shear strength, tensile resistance and compressive strength, respectively. Uniaxial compression and diagonal compression shear tests were performed on wallets and wall panels, respectively to determine compressive strength and shear strength of the adobe masonry. Finite element linear elastic analysis was conducted using ANSYS Finite-Element code to evaluate the stress state of loaded wall panels. The structural design of adobe masonry walls was carried out according to BS5628 and Eurocode 6 standards, by utilising material properties acquired from the experiments. The results showed that fiber inclusion in the mortar caused an increase in tensile strength of $31 \%$, friction
\end{abstract}


coefficient of $22 \%$, and prism compressive strength of $25 \%$ compared with unreinforced mortar. The reinforced wallets exhibited a twofold increase in compressive strength while reinforced wall panels indicated threefold increase in shear strength. The stress state in the reinforced and unreinforced wall panels was not a pure shear state and was better described by RILEM recommendations. The allowable vertical load resistance was found to be $40 \mathrm{kN} / \mathrm{m}$ and $100 \mathrm{kN} / \mathrm{m}$ for unreinforced and reinforced walls, respectively. The allowable lateral shear resistance was found to be $25 \mathrm{kN} / \mathrm{m}$ and $80 \mathrm{kN} / \mathrm{m}$ for unreinforced and reinforced walls, respectively. Reinforced masonry elements exhibited considerable ductility and unreinforced masonry elements showed brittle behaviour.

Keywords: Adobe bricks; Mortar; Masonry; Fiber reinforced soil; Sustainability *Corresponding author, E-mail:ikafodya@poly.ac.mw 


\section{Introduction}

Adobe is the oldest and widely used material for construction of dwelling houses. It is estimated that one third of the world's population and $50 \%$ of the population in the developing countries still live in the earthen buildings[1]. Earthen construction offers manifold benefits including cost effectiveness, lower embodied energy levels, high thermal mass and reduced use of nonrenewable materials[2-4]. The interest in earthen construction in the developed countries has been driven by the demands for more sustainable form of built environment. In this regard, earthen materials have been the attractive alternative to conventional high energy demand construction materials[2]. Moreover, it is expected that the earthen structures in developing countries will continue to exist not only due to their economic benefits, but also because of cultural tradition and identity attached to them[5]. The application of adobe materials faces several constraints due to their brittle behaviour, low tensile strength and deterioration when exposed to moisture. However, the properties of adobe can be improved by mechanical compaction, chemical stabilisation with cement, lime and bitumen, and fiber inclusions such as

straw $[3,6]$. Chemical stabilisation can significantly improve strength and water resistance of adobe. Typically, chemical binders are added at the contents between 4 and $10 \%$ of the soil dry weight $[7,8]$. On the other hand, the use of these additives significantly increases both material cost and environmental impact. Alternatively, natural fiber inclusions have been used in earthen construction to increase ductility, tensile strength, postcrack strength, erosion resistance, dimensional stability and reduce shrinkage cracks of the material[4].

The previous studies $[9,10]$ focused on the solution to improve mechanical properties of adobe bricks with natural fibers and chemical additives. The existing literature $[11,12]$ reports much on 
the seismic behaviour of adobe structures and the development of seismic strengthening solutions. In practice, the performance of adobe masonry in tension and shear is governed by the properties of the mortar [13]. Therefore, it is recommended that the strength of the mortar should be less than the strength of masonry units. On the contrary, some proposals have promoted the use of mortars with strengths similar to or greater than the bricks. To date, there is little published scientific data to support these recommendations or published design values for flexural bond strength of adobe brick masonry [2]. The study on cement stabilised mortar shows that tensile bond strength of cement mortar and adobe bricks/blocks varies between 0.007 and $0.032 \mathrm{MPa}$ and flexural bond strength between 0.004 and $0.014 \mathrm{MPa}[2]$. The bonding properties of unstabilised mortar with adobe bricks/blocks have not been extensively reported. In particular, synergic strength contributions of fiber reinforced mortar and adobe bricks/blocks to the global performance of the adobe masonry structures have not been reported in the literature. The adobe masonry structures are poorly constructed in the developing countries due to lack of design and construction guidelines. This has rendered the structures vulnerable to natural hazards such as earthquakes[14].

This study aimed at providing information on the mechanical properties of fiber reinforced adobe masonry construction for the design of resilient and sustainable low-cost infrastructure. Sisal fibers were used to reinforce mud mortar and adobe bricks. The study focused on the investigation into the effect of fiber inclusion in mud mortar and adobe bricks on the strength improvement of the adobe masonry structure. This was achieved by performing series of masonry element tests such as prism, triplet and couplet to determine compressive, shear and tensile strengths, respectively. The uniaxial compression test on wallets and diagonal compression (shear) test on masonry wall panels were performed to determine compressive 
strength and shear resistance of the adobe masonry structures. A finite element analysis of the wall panels was conducted to evaluate the stress state of the loaded reinforced and unreinforced masonry wall panels. The results of numerical analysis were compared with ASTM and RILEM interpretations using Mohr circles. Finally, design of the masonry walls was carried out according to BS5628 and Eurocode 6 standards in order to estimate load carrying capacity of the full scale adobe wall.

\section{Materials and experimental programme}

\subsection{Materials}

The soil used to manufacture adobe bricks was locally collected and air dried for $48 \mathrm{~h}$. The soil was manually sieved to remove any organic particles. Wet sieving for the soil was eventually carried out in accordance with ASTM D1140-17 and the grading curve of the soil is shown in Fig. 1.

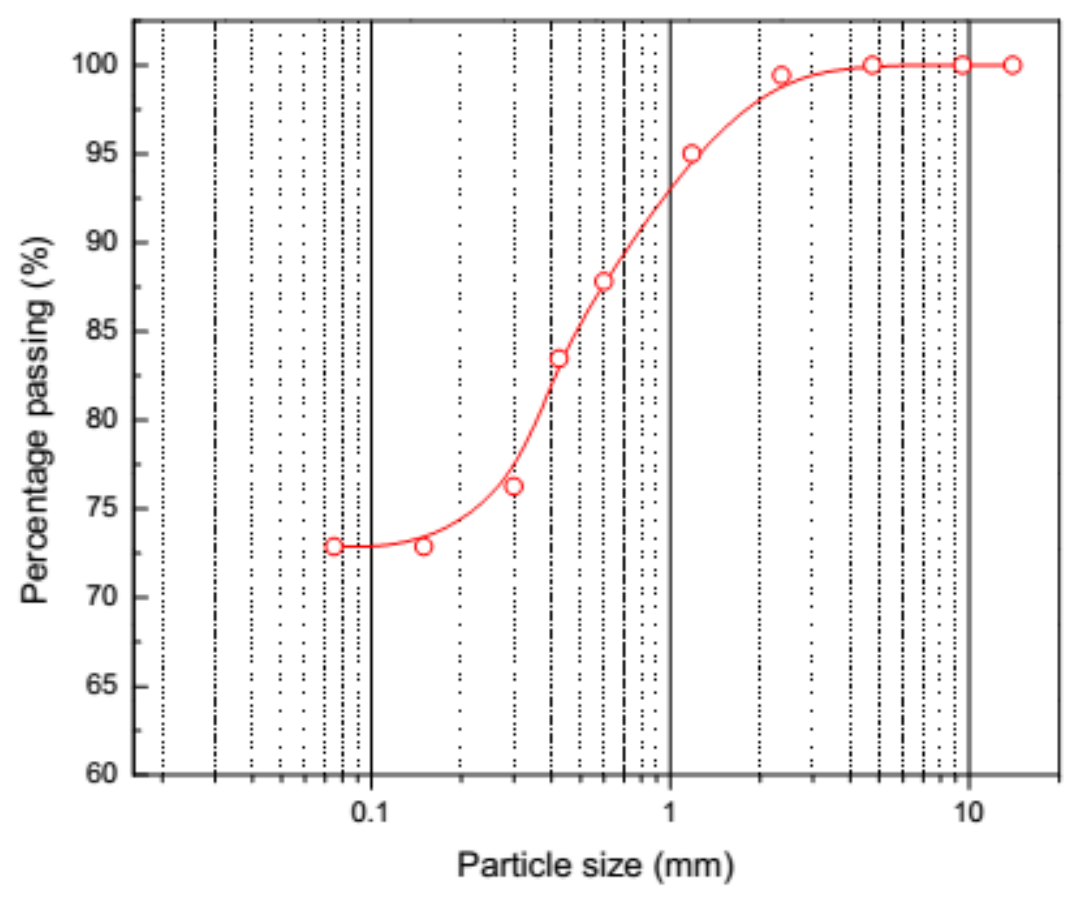

Fig. 1 Grading curve of the soil 
The soil is classified as CL in accordance with Unified Soil Classification System (USCS). The average diameter of particles at $\mathrm{D}_{50}$ is less than $0.075 \mathrm{~mm}$. The soil properties are summarised in Table 1.

Table1 Soil properties used in the study

\begin{tabular}{ll}
\hline Soil properties & Value \\
\hline Specific gravity & 2.7 \\
Consistency limits & \\
Liquid limit (\%) & 40 \\
Plastic limit (\%) & 21 \\
Plasticity Index & 19 \\
Linear shrinkage (\%) & 12 \\
USCS & $\mathrm{CL}$ \\
& \\
Compaction test & \\
$\mathrm{Maximum}$ dry unit weight $\left(\mathrm{kN} / \mathrm{m}^{3}\right)$ & 17.61 \\
Optimum moisture content $(\%)$ & 17 \\
& \\
Mineral composition (\%) & \\
$\mathrm{Al}_{2} \mathrm{O}_{3}$ & 17.05 \\
$\mathrm{CaO}$ & 8.82 \\
$\mathrm{SiO}_{2}$ & 56.54 \\
$\mathrm{Fe}_{2} \mathrm{O}_{3}$ & 7.48 \\
$\mathrm{MgO}_{\mathrm{K}} \mathrm{O}$ & 0.78 \\
\hline
\end{tabular}

Commercially available fiber used herein was sisal that was supplied by a South African company in the form of ropes. The fibers were cut into specified length of $25 \mathrm{~mm}$. Single fiber tensile tests were conducted to determine fiber mechanical properties and the summary of the results is shown in Table 2.

Table 2 Properties of the sisal fiber used for study.

\begin{tabular}{lc}
\hline Fiber property & Value \\
\hline Breaking tensile strength (MPa) & 500 \\
Elongation at break (\%) & 2.1 \\
Average diameter (mm) & 0.2 \\
Young's Modulus (GPa) & 23 \\
\hline
\end{tabular}




\subsection{Preparations and characterisation of masonry constituents}

The constituents of masonry elements comprised of reinforced and unreinforced mud mortar and adobe bricks. In the manufacture of adobe bricks, dry soil was weighed in the gauge box of dimensions $300 \times 300 \times 300 \mathrm{~mm}$. The prescribed fiber content $(0.75 \%)$ for the adobe composite mix was subsequently determined by the percentage of dry mass of soil, given by Eq. 1 .

$$
\rho=\frac{m_{f}}{m_{s}}
$$

where $m_{f}$ is the total mass of fibers and $m_{s}$ is the mass of the soil in the gauge box.

The soil was mixed with water at the moisture content of $+2 \%$ plastic limit and fibers were gradually added to wet soil until a homogeneous composite paste was formed. The soil paste was cast into a mould of dimensions $215 \times 102 \times 65 \mathrm{~mm}$ according to BIS recommendation and was immediately demoulded to produce adobe brick. The adobe bricks produced (see Fig. 2) were covered with grass and sun dried for 28days.
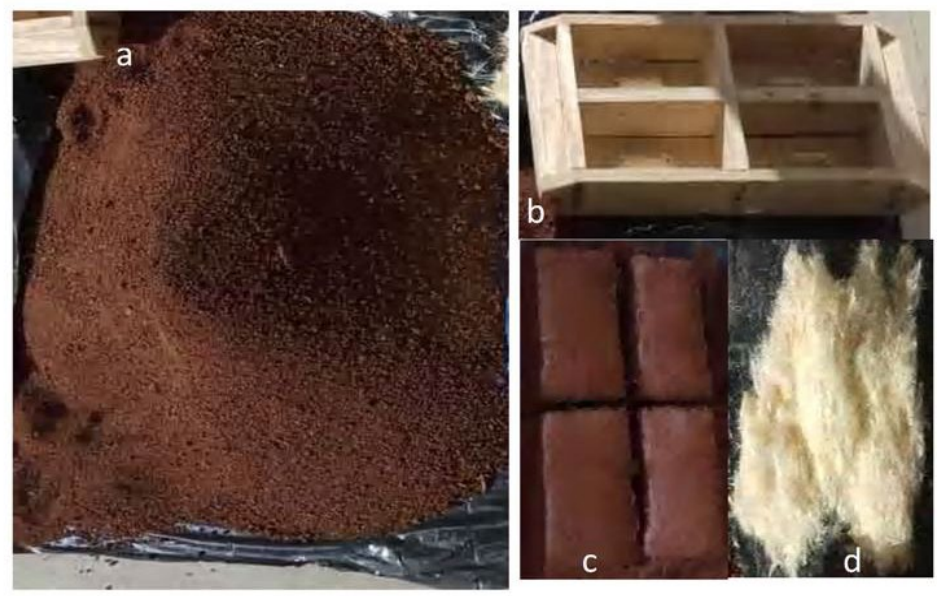

Fig. 2 (a) Soil sample (b) mould (c) manufactured adobe bricks (d) sisal fibers used

After drying, the average dimensions of the adobe bricks were reduced to $200 \times 100 \times 60 \mathrm{~mm}$ due to shrinkage of the material. The local methods for moulding and curing of adobe bricks were adopted to emulate common practice in rural areas of the Eastern and Southern regions of Africa. 
The unreinforced adobe bricks were also manufactured by following the same moulding and curing procedures.

The fiber reinforced and unreinforced mud mortar were also prepared and cast into cubes of 50x50x50mm. The mud mortar specimens were prepared in the same manner as the bricks. A total of 6 specimens per mortar type were prepared and cured for 28days under uncontrolled laboratory temperature. This number of specimens was selected in order to obtain good statistical data of the test results. The compression tests were performed on mortar and adobe bricks in order to characterise their strength properties. The irregularities of manufactured adobe brick specimens were smoothened by abrasion before testing to avoid pre-mature failure. The typical strength properties for mortar and adobe bricks used for masonry specimens are shown in Fig. 3.

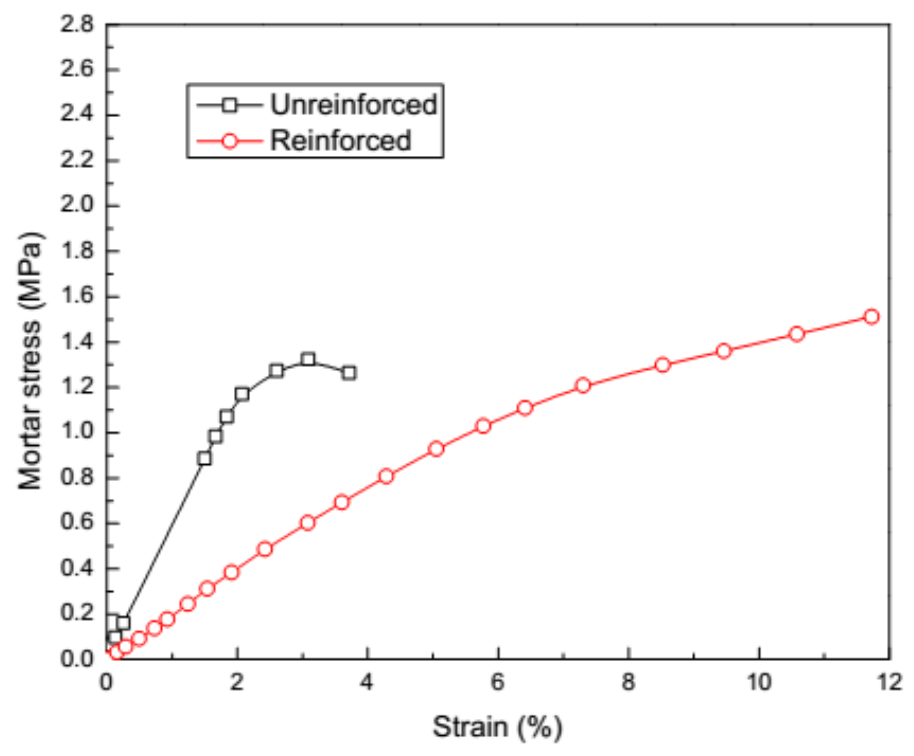

(a)

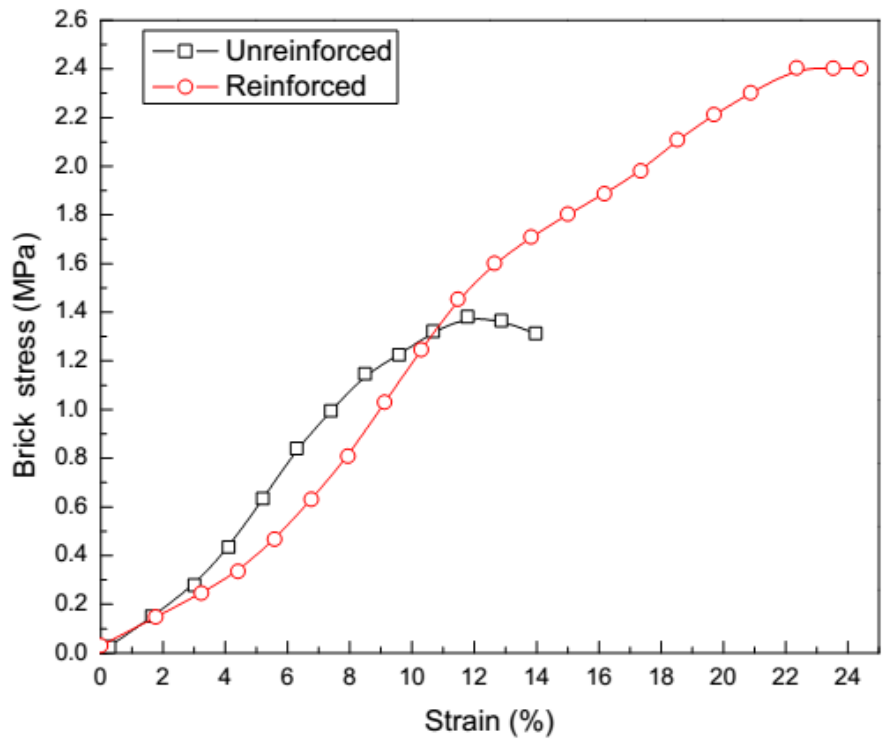

(b)

Fig. 3 (a) Typical properties of mortar (b) Typical properties of adobe bricks. 


\subsection{Specimen preparation for adobe masonry testing}

Masonry elements, namely prisms, triplets and couplets were prepared using the manufactured adobe bricks and aforementioned mortar types (reinforced and unreinforced). Different reinforcement patterns for the prism specimens were adopted. The specimens' reinforcement patterns were as follows; (a) reinforced brick and mortar (coded as RBRM), (b) unreinforced brick and reinforced mortar (coded as UBRM), (c) reinforced brick and unreinforced mortar (coded as RBUM) and, (d) unreinforced mortar and bricks (coded as UBUM). The variations in the reinforcement patterns of masonry prism components aimed at determining the optimum fiber reinforcement design for masonry construction. The masonry elements were cured for 28days under uncontrolled laboratory temperature.

Two sets of wallets of average dimensions of 500x480x200mm were prepared, one with both reinforced mortar and bricks that was labeled as (RMRB) and the other with both unreinforced mortar and bricks that was labeled as (UMUB). The wall panels of average dimensions of 1080x1100x 100mm were prepared. Since failure of the wall panels in diagonal shear is governed by strength of the mortar [15], the panel reinforcement was applied to mortar only. The unreinforced adobe bricks were used to prepare panel specimens according to RILEM[16] recommendation. The panel specimens were labeled as UBUM and UBRM to stand for the

unreinforced and reinforced panels, respectively. The local procedure used in the Eastern and Southern Africa for masonry construction was adopted. A total of 3 specimens per type were prepared for both wallet and panel testing.

\subsection{Experimental programme}

The compression test of adobe bricks was carried out using Coopers TC4131 compression machine at the stress rate of $0.5 \mathrm{kPa} / \mathrm{s}$ according to ASTMC67-03a [17]. Compression test on 
mortar specimens was performed using Quasar 10 universal tensile machine at a loading rate of $0.5 \mathrm{~mm} / \mathrm{min}$ according to BS EN1015-11 [18]. The average compressive strength value of 6 tested specimens was determined and taken as representative strength of materials for both bricks and mortar.

The tension capacity of mortar was determined by a series of couplets tests using fabricated test rig. The test set-up for couplets is shown in Fig. 4.

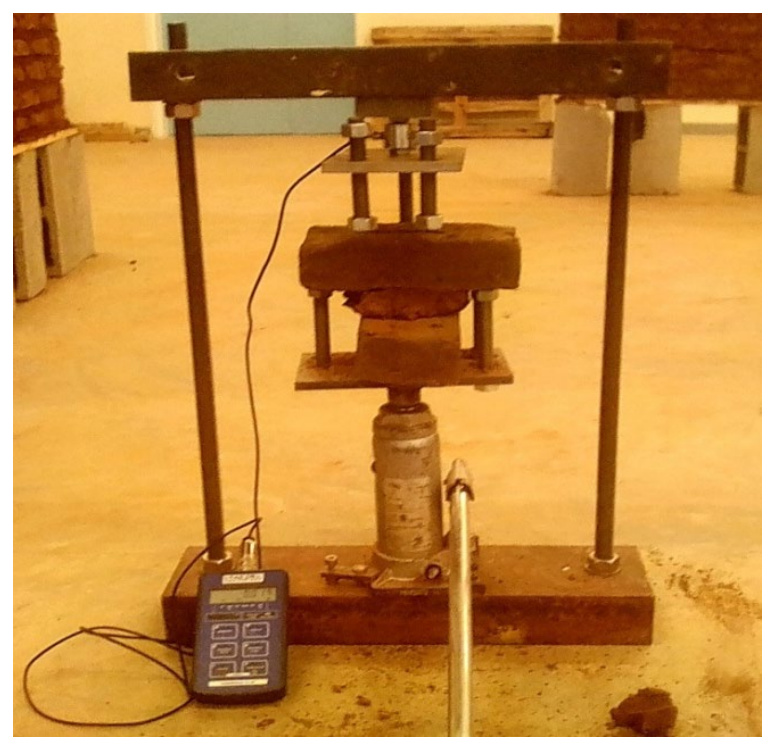

Fig. 4 Test set-up for mortar couplet test

The tension bond resistance of the mortar was computed as the sum of measured load and the selfweight of the bottom brick. The tensile bond strength was determined by dividing total load with mortar-brick contact area. The average strength value of 5 specimens of each mortar type was determined and taken as representative strength of the material.

The prism and triplet tests were conducted according to ASTM C1314-03b and BS EN 10521053 [19] [20], respectively. The triplet was realised with three bricks and two mortar joints. The wooden blocks of $50 \mathrm{~mm}$ width were placed under the lateral bricks and the load was applied on 
top of the central brick. Three lateral confinement stresses of $0.025 \mathrm{kPa}, 0.05 \mathrm{kPa}$ and $0.1 \mathrm{kPa}$ were applied to determine the coefficient of friction and failure criteria of each mortar type. The test set-up for triplets is shown in Fig. 5.

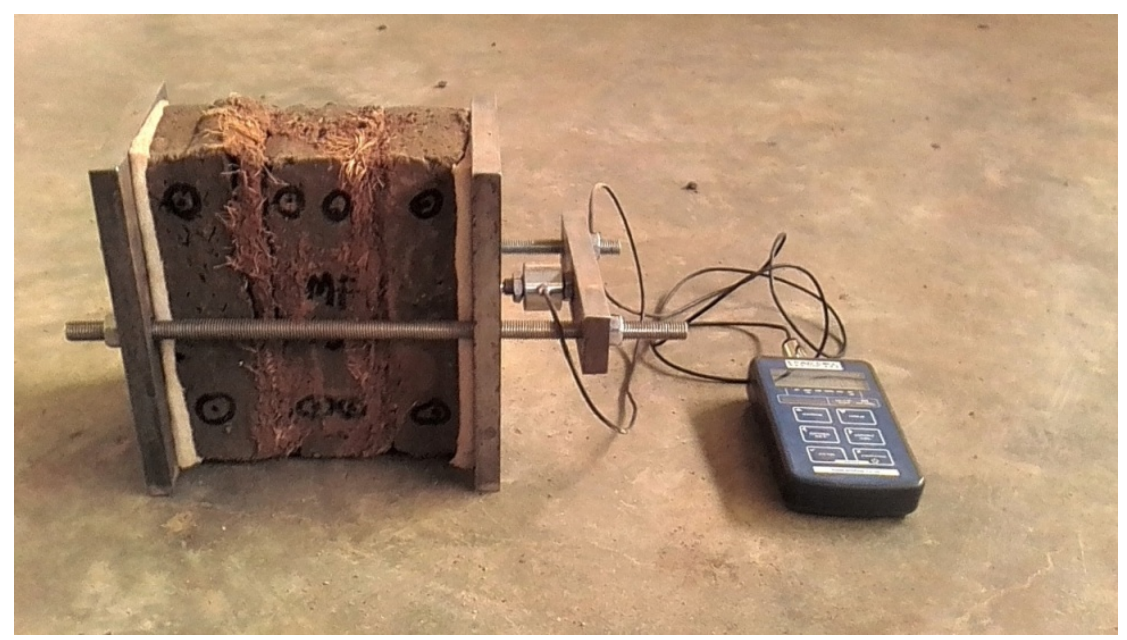

Fig. 5 Triplet test specimen and confinement frame.

The shear strength of the triplet was computed using Eq. 2.

$$
\tau_{t}=\frac{P_{u l t}}{2 A_{g}}
$$

where $\mathrm{P}_{\text {ult }}$ is the ultimate load and $\mathrm{A}_{\mathrm{g}}$ is the area parallel to the mortar joint.

Diagonal compression test was performed on wall panels to determine shear strength in accordance with [21]. The diagonal compression test set-up is shown in Fig. 6. 


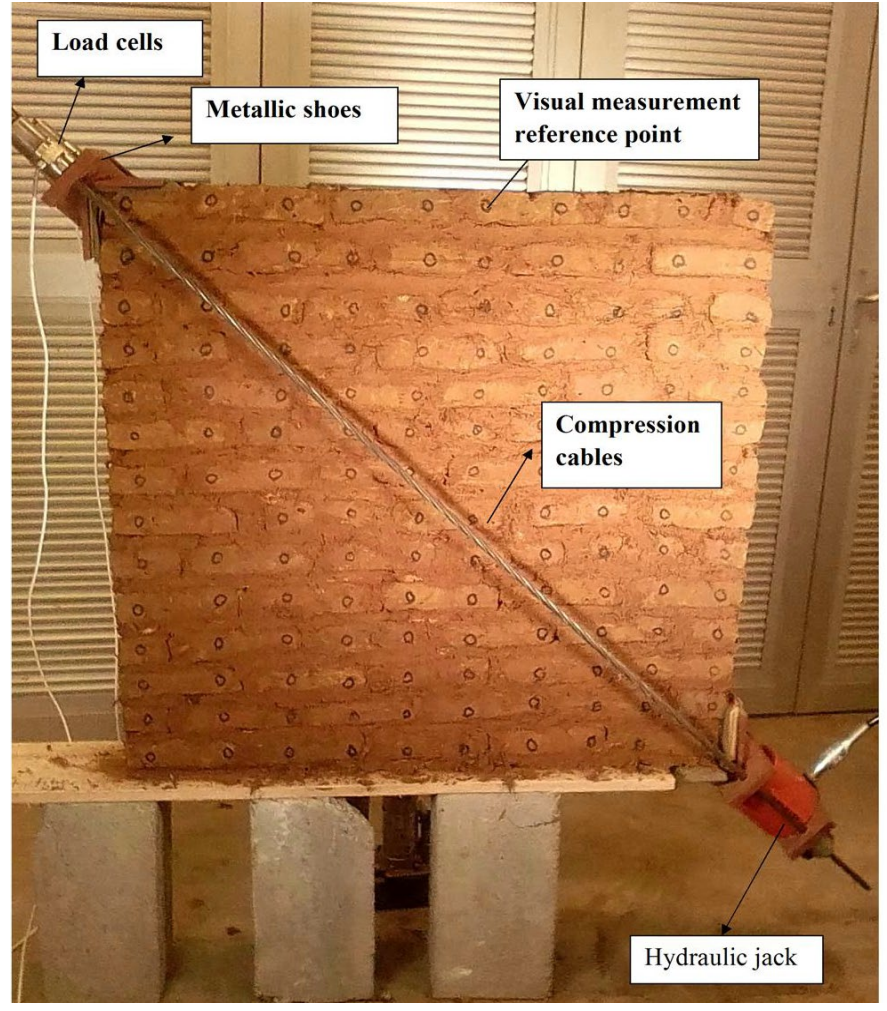

Fig. 6 Diagonal compression test set-up

The metallic shoes of length $1 / 10$ of the panel length were anchored to the lower and upper corners of the panel by the tension cables. The load cells and the metallic shoes were fixed to the cables by steel pins. The metallic shoes were used in order to distribute the load on a larger surface area to avoid concentration of compression stresses and, consequently, local failures at the corners. The diagonal compression load was applied on the lower corner of the wall by a hydraulic jack until failure of the panel occurred. Shear strength of the panel was computed using Eq. 3 according to ASTM.

$$
\tau_{p}=0.707 \frac{P_{t}}{A_{p}}
$$

where $\mathrm{P}_{t}$ is the ultimate failure load and $\mathrm{A}_{\mathrm{p}}$ is the net area of the panel. 
Displacements and strains of the prism, triplet and wall panel specimens were measured using an Imetrum Video Gauge system, during testing, along with the applied loads measured by calibrated load cells. Numerical simulation of the panels was performed by Finite-Element code ANSYS 14 in ANSYS Parametric Design Language (APDL). The objective was to evaluate the stress state of the wall panels by linear elastic analysis. Both bricks and mortar were modelled using four node triangular standard elements called Plane 183. These elements have two degrees of freedom per node, four Gauss integration points and Lagrangian polynomials as shape functions. The model of the masonry wall was built as a regular inclusion of bricks into a matrix of mortar. The mortar was perfectly bonded to bricks. The geometrical configuration and the boundary conditions were identical to the real experimental setup used in the laboratory testing. The maximum shear loads obtained from the experimental results were applied to the finite element model. The elastic material properties such as Young's modulus and Poison's ratio that were employed in the finite element analysis are summarised in Table 3.

Table 3 Material properties employed in finite element analysis of panels

\begin{tabular}{ccccc}
\hline Property & $\begin{array}{c}\text { Reinforced } \\
\text { mortar }\end{array}$ & $\begin{array}{c}\text { Unreinforced } \\
\text { mortar }\end{array}$ & Bricks & Ref \\
\hline $\begin{array}{c}\text { Elastic } \\
\text { Modulus (MPa) }\end{array}$ & 150 & 350 & 1500 & Experiment \\
Poison's ratio & 0.2 & 0.2 & 0.26 & \\
\hline
\end{tabular}

\section{Results and discussions}

\subsection{Couplet test}

The results of tensile capacity of both reinforced mortar (RM) and unreinforced mortar (URM) from couplet tests are shown in Table $4 \mathrm{a}$ and $4 \mathrm{~b}$. 
Table 4a Tensile bond resistance of fiber reinforced mud mortar

\begin{tabular}{cccc}
\hline Specimen Serial & $\begin{array}{c}\text { Maximum Tensile capacity } \\
(\mathrm{N})\end{array}$ & $\begin{array}{c}\text { Mean } \\
(\mathrm{N})\end{array}$ & $\begin{array}{c}\text { COV } \\
\%\end{array}$ \\
\hline RM1 & 32 & & \\
RM2 & 34 & 37 & \\
RM3 & 40 & & \\
RM4 & 41 & & \\
RM5 & 38 & & \\
\hline
\end{tabular}

*RM=Reinforced mortar

Table 4b Tensile bond resistance of unreinforced adobe mud mortar

\begin{tabular}{cccc}
\hline Specimen Serial & $\begin{array}{c}\text { Maximum Tensile capacity } \\
(\mathrm{N})\end{array}$ & $\begin{array}{c}\text { Mean } \\
(\mathrm{N})\end{array}$ & $\begin{array}{c}\text { COV } \\
\%\end{array}$ \\
\hline URM1 & 20 & & \\
URM2 & 21 & 28.2 & 26 \\
URM3 & 32 & \\
URM4 & 37 & \\
URM5 & 31 &
\end{tabular}

*URM=Unreinforced mortar

The tensile capacity values of reinforced specimens range between $32 \mathrm{~N}$ and $41 \mathrm{~N}$ while values of unreinforced specimens range between $20 \mathrm{~N}$ and $37 \mathrm{~N}$. The average tensile resistance values for both unreinforced and reinforced mortar types are $28.2 \mathrm{~N}$ and $37 \mathrm{~N}$, respectively. Fiber inclusion causes an increase in tensile capacity of about $31 \%$ compared with unreinforced specimens. The coefficient of variation (COV) of unreinforced specimens is $26 \%$ while that for reinforced specimens is $11 \%$. This implies that test results of unreinforced specimens exhibited higher dispersion than for reinforced ones. The fiber inclusion in mud mortar reduces shrinkage of the soil and also minimises size of shrinkage cracks [8]. The lower resistance exhibited by unreinforced mortar was due to the shrinkage of the mortar that undermined bonding at mortarbrick interface. The presence of shrinkage cracks caused pre-mature failure of the unreinforced mortar. The variations in the bonding properties of the unreinforced mortar resulted in the high dispersion of test results. On the other hand, the low shrinkage and significant tensile resistance of fibers were responsible for good bonding at the mortar-brick interface and high tensile resistance of the fiber reinforced mortar. 


\subsection{Triplet test}

The test results of shear strength of reinforced and unreinforced mortar types are shown in Tables $5 \mathrm{a}$ and $5 \mathrm{~b}$, respectively.

Table 5a Shear strength of reinforced mortar with various lateral confinement stresses

\begin{tabular}{cccc}
\hline \multirow{2}{*}{$\begin{array}{c}\text { Specimen } \\
\text { serial }\end{array}$} & 0.025 & Lateral confinement stress $(\mathrm{kPa})$ & 0.05 \\
\cline { 2 - 4 } & & Shear strength $(\mathrm{MPa})$ & \\
\hline 1 & 0.038 & 0.075 & 0.105 \\
2 & 0.035 & 0.077 & 0.105 \\
3 & 0.050 & 0.075 & 0.105 \\
\hline
\end{tabular}

Table 5b Shear strength of unreinforced mortar with various lateral confinement stresses

\begin{tabular}{cccc}
\hline \multirow{2}{*}{$\begin{array}{c}\text { Specimen } \\
\text { serial }\end{array}$} & 0.025 & Lateral confinement stress $(\mathrm{kPa})$ & 0.05 \\
\cline { 2 - 4 } & & Shear strength $(\mathrm{MPa})$ & 0.1 \\
\hline 1 & 0.028 & 0.035 & 0.083 \\
2 & 0.030 & 0.055 & 0.085 \\
3 & 0.038 & 0.055 & 0.080 \\
\hline
\end{tabular}

For the reinforced specimens, shear strength with lateral confinement stresses between $0.025 \mathrm{kPa}$ and $0.1 \mathrm{kPa}$ ranges between $0.035 \mathrm{kPa}$ and $0.105 \mathrm{kPa}$. On the other hand, the shear strength of unreinforced specimens with lateral confinement stresses between $0.025 \mathrm{kPa}$ and $0.1 \mathrm{kPa}$ ranges between $0.028 \mathrm{kPa}$ and $0.085 \mathrm{kPa}$. The shear strength values of adobe masonry between $0.014 \mathrm{kPa}$ and $0.05 \mathrm{kPa}$ are reported in the literature [22]. The marginal difference between the literature and the test results is attributed to the type of soil and the lateral confinement stresses imposed on the specimens in the present study. The corresponding Mohr-Coulomb failure criteria for both mortar types are shown in Fig. 7. 


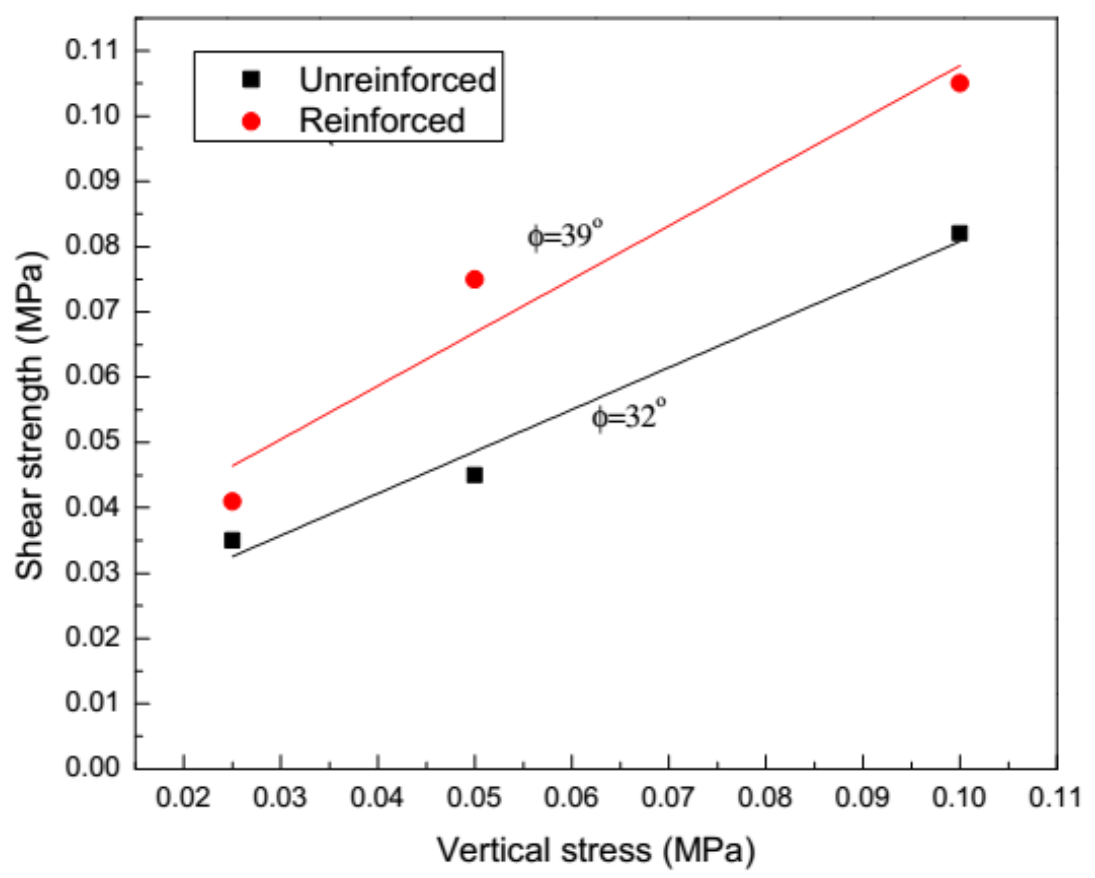

Fig. 7 Mohr-coulomb failure criteria for triplets with reinforced and unreinforced mortar

It is shown that an increase in lateral confinement stress causes an increase in shear strength. It is worth noting that the angles of friction for reinforced and unreinforced specimens are $39^{\circ}$ and $32^{\circ}$, respectively. In comparison, fiber reinforced specimens indicate an average increase in shear strength of about $22 \%$ relative to unreinforced specimens. The cohesion of about $0.037 \mathrm{MPa}$ and $0.025 \mathrm{MPa}$ for reinforced and unreinforced mortar respectively, are indicated. The angles of friction between $29^{\circ}$ and $34^{\circ}$, and cohesion values between $0.037 \mathrm{MPa}$ and $0.045 \mathrm{MPa}$ for unreinforced adobe specimens are reported in the literature[22]. It is noted that the test results in the present study are relatively close to what has been reported in the literature. It is evident that fibers endowed the mortar with significant shear strength and friction coefficient. This was attributed to the mechanical interaction between fibers and soil particles that ultimately mobilised resistance to applied shear. The fibers provided large friction surface area with soil particles hence enhanced friction resistance of the fiber composite. 


\subsection{Prism test}

The results of compressive strength and strain of masonry prisms for specimens with unreinforced mortar and bricks (UBUM), specimens with unreinforced bricks and reinforced mortar (UBRM), specimens with reinforced bricks and unreinforced mortar (RBUM) and specimens with reinforced bricks and mortar (RBRM) are shown in Fig. 8.

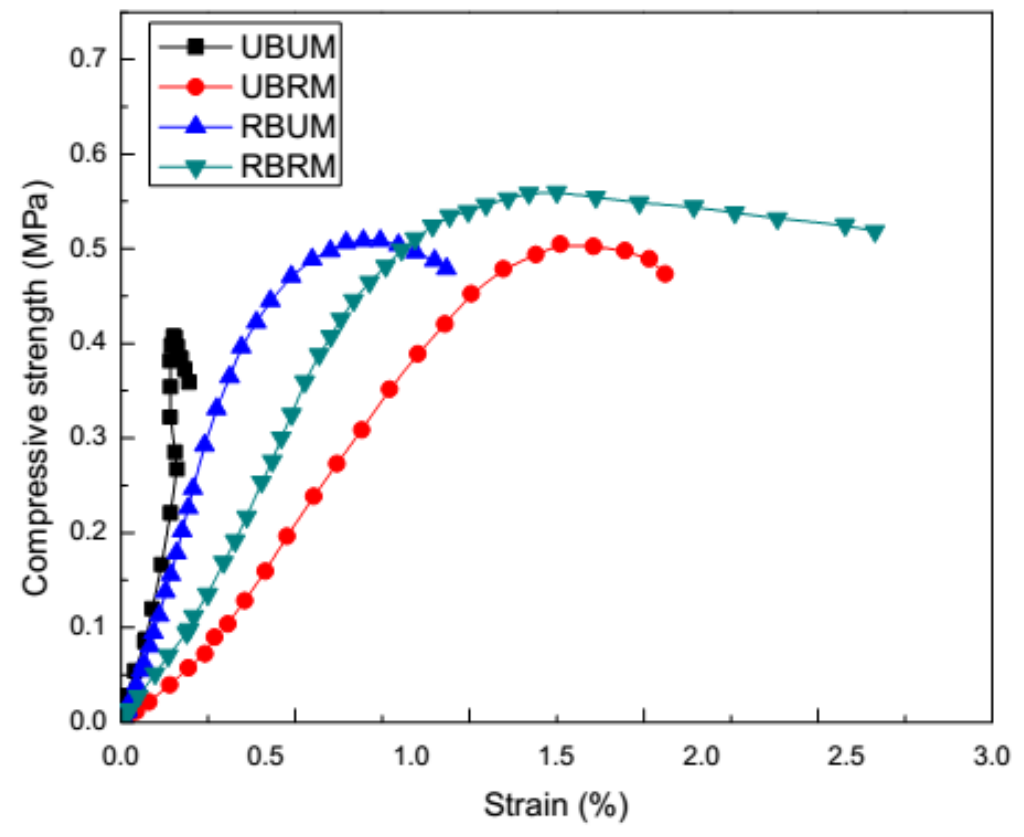

Fig. 8 Stress-strain relationship of masonry prisms

It is shown that compressive strength of reinforced prisms increases linearly to yield strain and reduces to failure strain. The unreinforced prisms fail immediately after reaching yield strain which is an indicative of brittle behaviour. In comparison, prisms with unreinforced mortar mobilise low strength compared with reinforced prisms. It is shown that reinforced prisms exhibit strength increase of a minimum of $25 \%$ relative to unreinforced prisms. The ductility increases with fiber inclusion in either the mortar or the bricks. Almost the same compressive strength of about $0.5 \mathrm{MPa}$ is mobilised with fiber inclusion in either the mortar or bricks. The 
prisms with fiber reinforced mortar and bricks show the highest ductility and strength of about 0.55MPa. The yield strain values for UBUM, RBUM, UBRM and RBRM are $0.15 \%, 0.5 \%, 1.2 \%$ and $1.2 \%$, respectively. It is noted that the strength and deformation of the masonry prisms increase with fiber inclusion especially in the mortar. Nazeen et al [23] reported that strength of the masonry increases with an increase in strength of the mortar. Vicentan and Torrealva [22, 24] in a similar experimental investigation reported values of prism compressive strength of the traditional adobe in the range between $0.36 \mathrm{MPa}$ and $1 \mathrm{MPa}$, and strain between $0.5 \%$ and $3 \%$. It is noted that the test results are within the values reported in the literature however, the prism compressive strength of adobe masonry depends on the properties of adobe material. The high load carrying capacity of reinforced mortar was responsible for strength improvement of the masonry prisms. The reinforced bricks provided additional strength to the masonry. It can be concluded that the strength of both bricks and mortar had similar influence on the overall strength of the masonry. The typical failure modes of the masonry prisms with unreinforced mortar and bricks (UBUM), with unreinforced bricks and reinforced mortar (UBRM) and those with reinforced bricks and mortar (RBRM) are shown in Fig. 9.

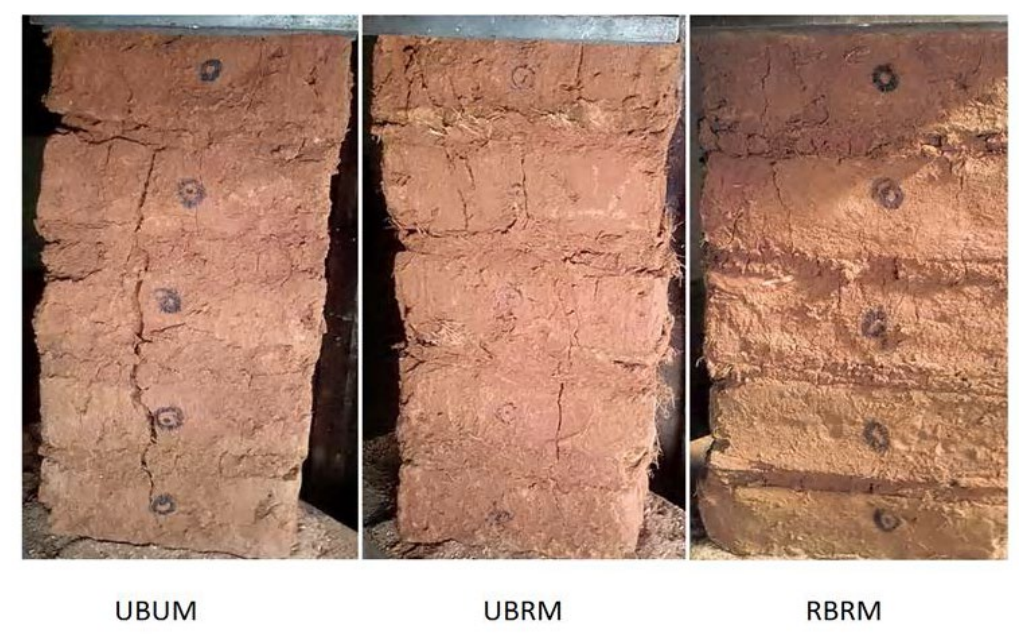

Fig. 9 Failure modes of masonry prisms 
It is noted that typical failure mode of unreinforced masonry is characterised by vertical crack across the bricks and mortar joints. Feng Wu [24] also reported similar failure modes of the masonry prisms. In case of the partially reinforced prisms (UBRM), the failure mode is characterised by vertical cracks relatively smaller than those of unreinforced prisms. For the fully reinforced prisms (RBRM), the failure is characterised by both vertical and horizontal cracks accompanied by large lateral deformation. The ductility is advantageous to seismic performance of the reinforced masonry. It implies that the reinforced adobe masonry structure would undergo considerable deformation before collapse during earthquake [25].

\subsection{Wallet compression test}

The results of the compressive strength of masonry wallets for reinforced (RBRM) and unreinforced specimens (UBUM) are shown in Table 6.

Table 6.Results of compressive strength of fiber reinforced and unreinforced masonry wallets

\begin{tabular}{cccccc}
\hline $\begin{array}{c}\text { Specimen } \\
\text { designation }\end{array}$ & $\begin{array}{c}\text { Dimensions } \\
h \times w \times t(m m)\end{array}$ & $\begin{array}{c}\text { Maximum } \\
\text { compressive } \\
\text { load } \\
(\mathrm{kN})\end{array}$ & $\begin{array}{c}\text { Compressive } \\
\text { strength } \\
(\mathrm{MPa})\end{array}$ & $\begin{array}{c}\text { Mean } \\
(\mathrm{MPa})\end{array}$ & $\begin{array}{c}\text { COV } \\
\%\end{array}$ \\
\hline RMRB1 & $480 \times 400 \times 202$ & 126 & 1.3 & & \\
RMRB2 & $480 \times 401 \times 205$ & 124 & 1.26 & 1.3 & \\
RMRB3 & $500 \times 400 \times 209$ & 140 & 1.33 & & \\
& & & & & \\
UMUB1 & $502 \times 400 \times 210$ & 68 & 0.65 & 0.53 & \\
UMUB2 & $515 \times 410 \times 208$ & 48 & 0.45 & & \\
UMUB3 & $520 \times 410 \times 210$ & 56 & 0.51 & & \\
\hline
\end{tabular}

The compressive strength values of the reinforced wallets range between $1.26 \mathrm{MPa}$ and $1.33 \mathrm{MPa}$ with coefficient of variation of $2.7 \%$. On the other hand, compressive strength of unreinforced wallets ranges between $0.45 \mathrm{MPa}$ and $0.65 \mathrm{MPa}$ with coefficient of variation of $19 \%$. In comparison, the compressive strength values of adobe wallets between $0.77 \mathrm{MPa}$ and $1.72 \mathrm{MPa}$ are reported in the literature [26]. It is worth noting that compressive strength results from the tests are within the range reported in the literature. It is worth noting that fiber inclusions in the 
mortar and bricks cause an average increase in the compressive strength of the wallets of about $145 \%$ as compared with unreinforced wallets. The results of fiber reinforced masonry wallets show small coefficient of variation $(2.7 \%)$ while the unreinforced masonry wallets indicate large coefficient of variation (19\%). The shrinkage cracks might result in non-uniform material properties and pre-mature failure, and hence were responsible for the scatter of test results for unreinforced wallets. The material homogeneity reduced scatter of the reinforced wallets test results. Failure mode of the reinforced wallets was characterised by large deformation with vertical cracks. On the other hand, unreinforced wallets failed by crushing of the bricks and mortar, as shown in Fig. 10.

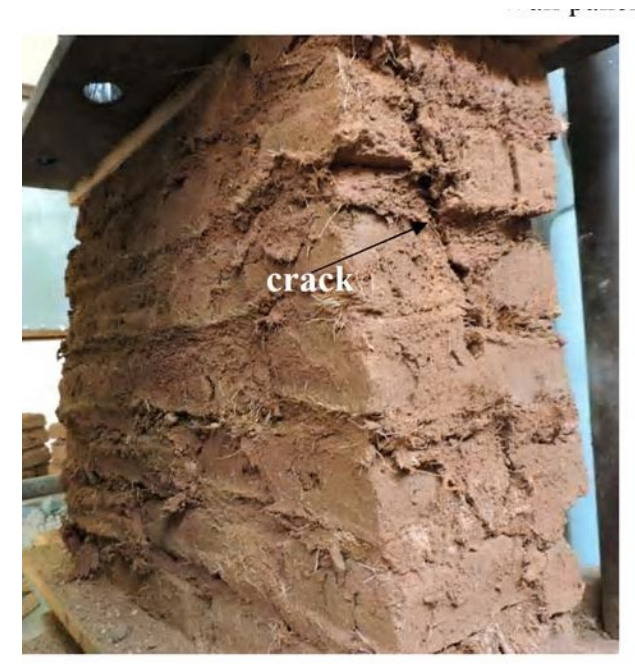

(a)

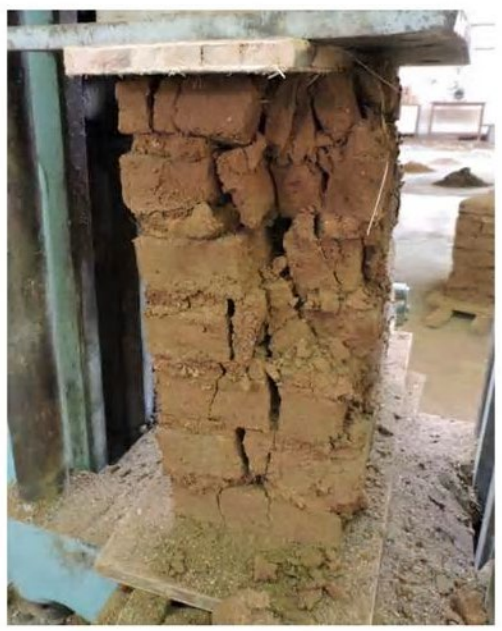

(b)

Fig. 10 Failure modes of wallets (a) reinforced (b) unreinforced

\subsection{Diagonal compression panel test}

The results of diagonal compression shear strength for reinforced (RBRM) and unreinforced (UBUM) panels are shown in Table 7. 
Table 7 Results of diagonal compression test

\begin{tabular}{cccccccc}
\hline $\begin{array}{c}\text { Specimen } \\
\text { designation }\end{array}$ & $\begin{array}{c}\text { Maximum } \\
\text { shear } \\
\text { strength }(\tau) \\
(\mathrm{MPa})\end{array}$ & $\begin{array}{c}\text { Maximum } \\
\text { Diagonal } \\
\text { Shear load } \\
(\mathrm{kN})\end{array}$ & $\begin{array}{c}\text { Shear } \\
\text { modulus } \\
(G) \\
(\mathrm{MPa})\end{array}$ & $\begin{array}{c}\text { Mean } \\
\text { shear } \\
\text { strength } \\
(\mathrm{MPa})\end{array}$ & $\begin{array}{c}\text { Mean shear } \\
\text { modulus } \\
(\mathrm{MPa})\end{array}$ & $\begin{array}{c}\text { COV } \\
\text { shear } \\
\text { strength } \\
\%\end{array}$ & $\begin{array}{c}\text { COV shear } \\
\text { modulus } \\
\%\end{array}$ \\
\hline UBRM1 & 0.043 & 73.6 & 21.76 & & & \\
UBRM2 & 0.041 & 70.2 & 42.21 & 0.047 & 41.60 & 13 \\
UBRM3 & 0.056 & 95.8 & 60.78 & & & \\
UBUM1 & 0.016 & 27.4 & 6.48 & & & \\
UBUM2 & 0.012 & 20.5 & 13.96 & 0.014 & & \\
UBUM3 & 0.014 & 24 & 7.52 & & & & \\
\end{tabular}

The diagonal compression shear strength values of the reinforced panels range between $0.041 \mathrm{MPa}$ and $0.056 \mathrm{MPa}$ with coefficient of variation of $13 \%$. The diagonal shear modulus of reinforced panels ranges between $21.76 \mathrm{MPa}$ and $60.78 \mathrm{MPa}$. On the other hand, diagonal compression shear strength of unreinforced panels ranges between $0.012 \mathrm{MPa}$ and $0.016 \mathrm{MPa}$ with coefficient of variation of $12.6 \%$. The diagonal shear modulus of unreinforced panels is between $6.48 \mathrm{MPa}$ and $13.96 \mathrm{MPa}$. It is noted that reinforced panels exhibit an avaerage increase in shear strength and shear modulus of $235 \%$ and $346 \%$, respectively compared with unreinforced panels. The shear stress and strain relationships of both reinforced (RBRM) and unreinforced (UBUM) panels are shown in Fig. 11.

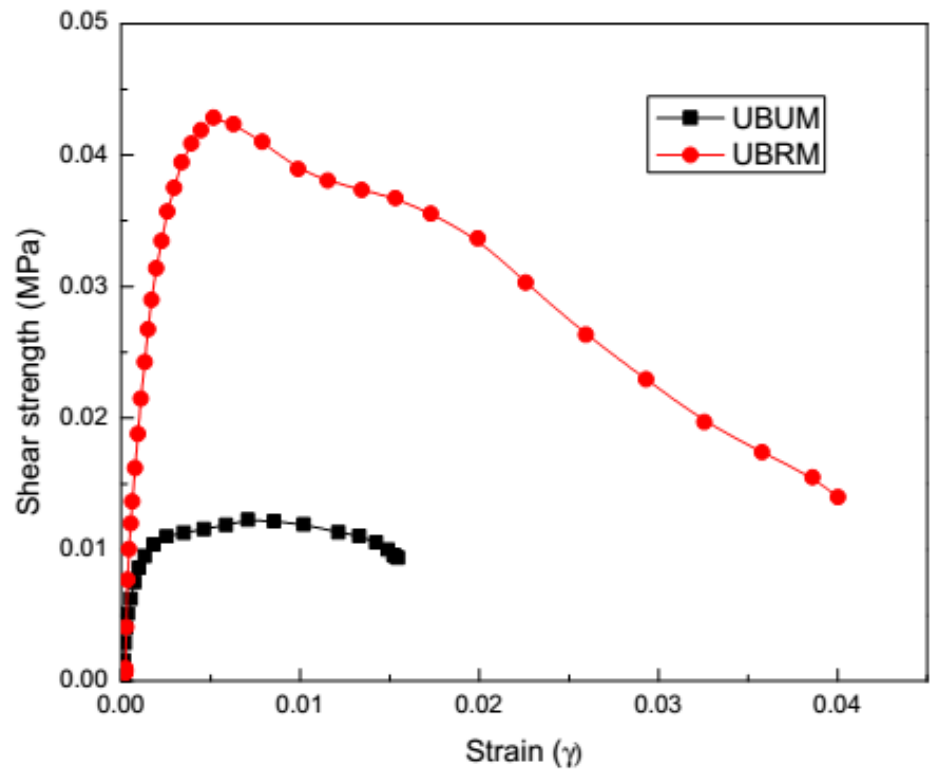


Fig. 11 Shear strength and strain relationship of panels

It is noted that reinforced panels exhibit considerable ductility before collapse while unreinforced panels show brittle behaviour. The failure modes of both unreinforced and reinforced panel are characterised by the diagonal crack inclined at almost $45^{\circ}$ to the horizontal plane of the panel, as shown in Fig. 12a and 12b.

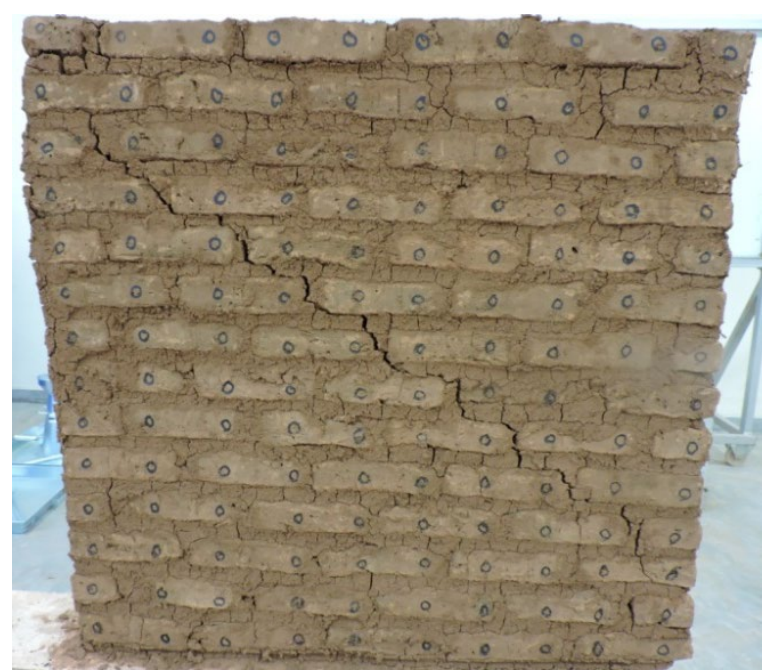

(a)

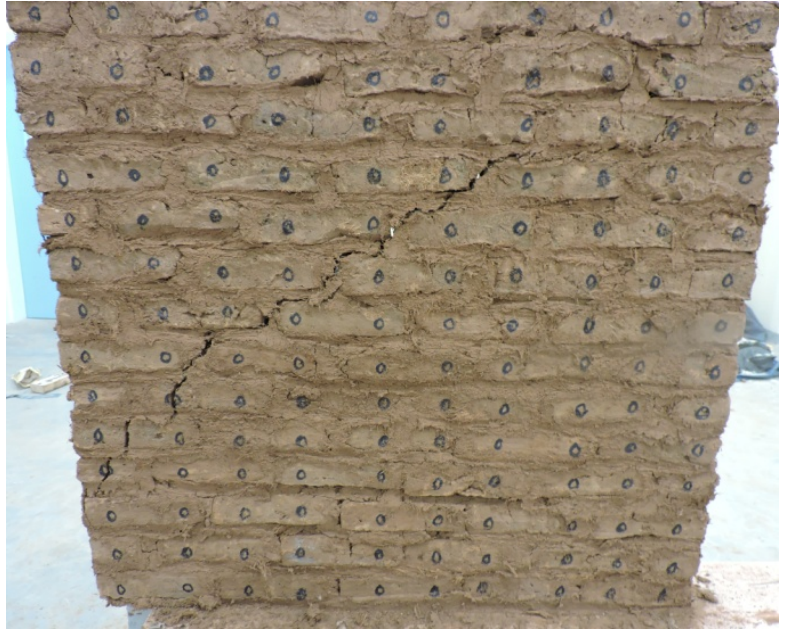

(b)

Fig. 12 (a) Failure of unreinforced panel (b) Failure of reinforced mortar.

The failure modes imply that the major principal tensile stress in this test coincided with the inclination of the crack. It is anticipated that reinforced panel would perform better to lateral loading such as seismic loading.

\subsection{Finite element analysis of the wall panels}

Finite element modelling was undertaken by imposing loads from the experimental results $(81 \mathrm{kN}$ and $25 \mathrm{kN}$ for reinforced and unreinforced panels, respectively). The major principal tensile stress was assumed to be concentrated at the center of the panel $[15,27,28]$. The modelling scheme of the panel is shown in Fig. 13a and 13b. 


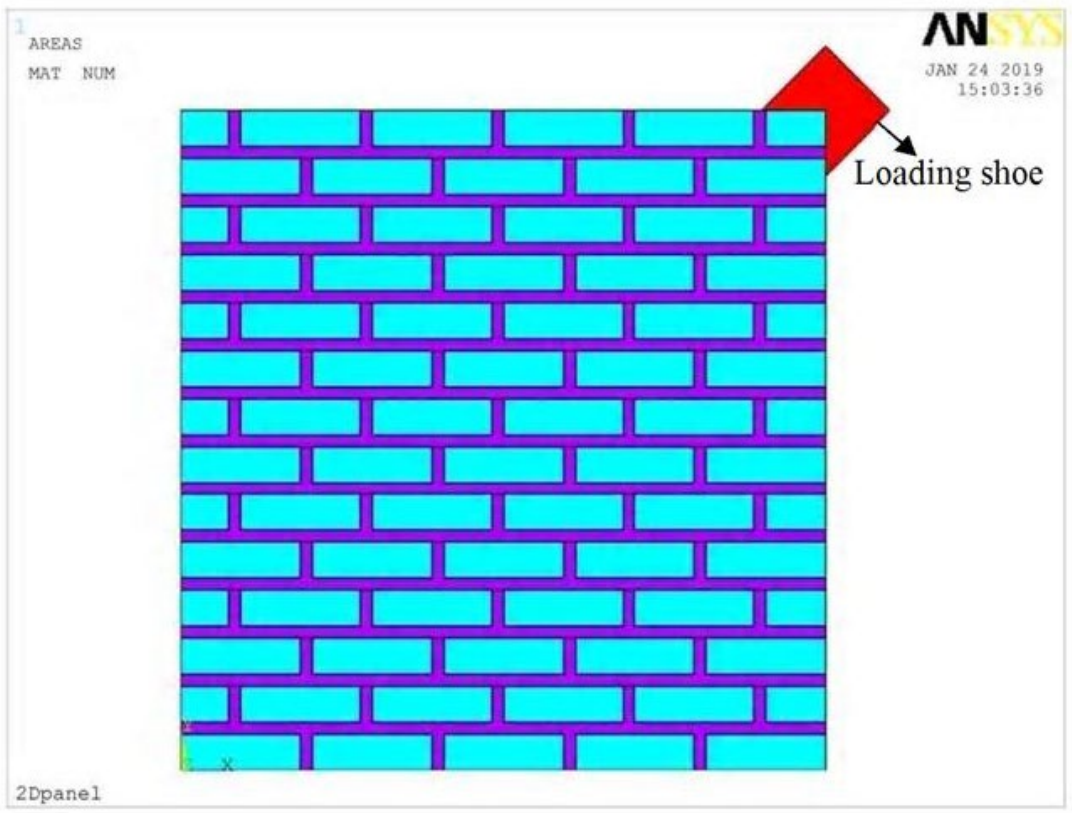

(a)

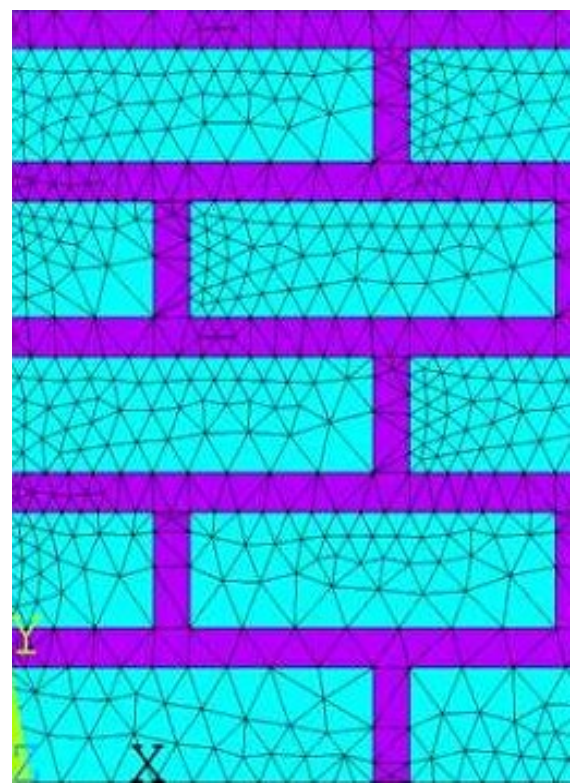

(b)

Fig. 13 (a) Finite Element Analysis Model (b) Triangular element mesh

The results of the finite element linear elastic analysis for unreinforced are shown in Fig. 14a, 14b, 14c and 14d. The results for reinforced panel are shown in Fig. 15a, 15b, 15c and 15d. 


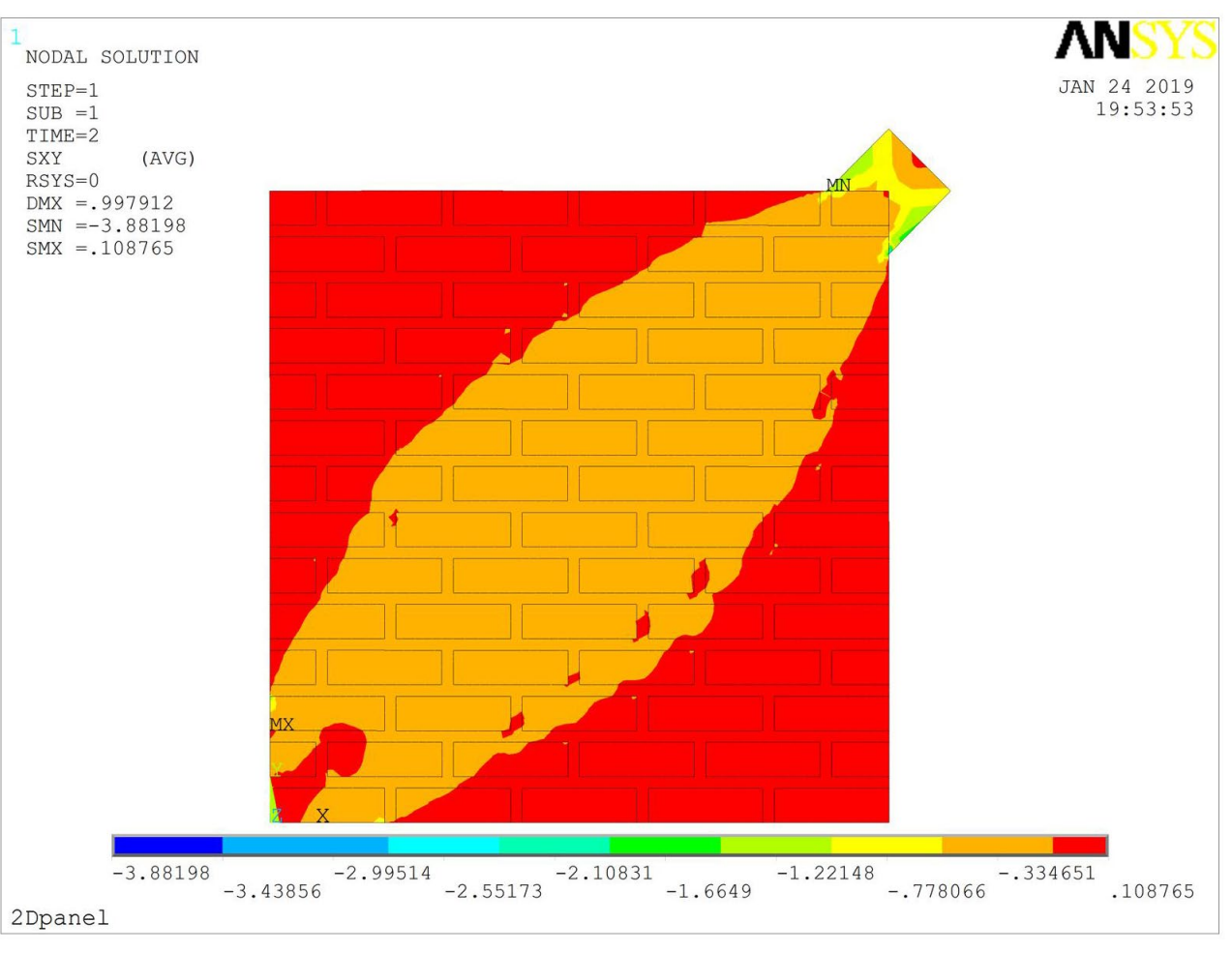

(a)

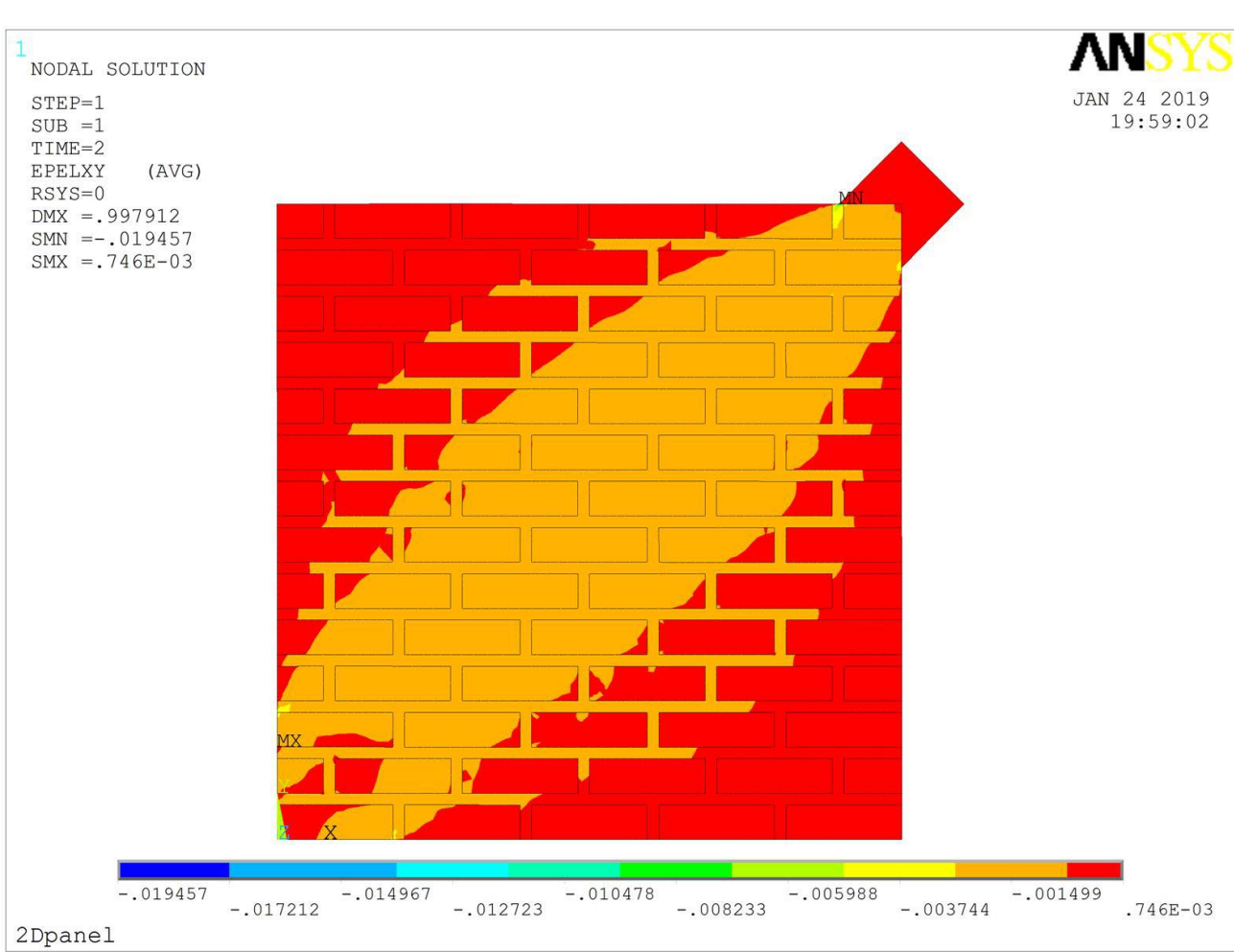

(b)

Fig. 14 (a) Shear stress distribution of unreinforced panel

(b) Shear strain distribution of unreinforced panel 


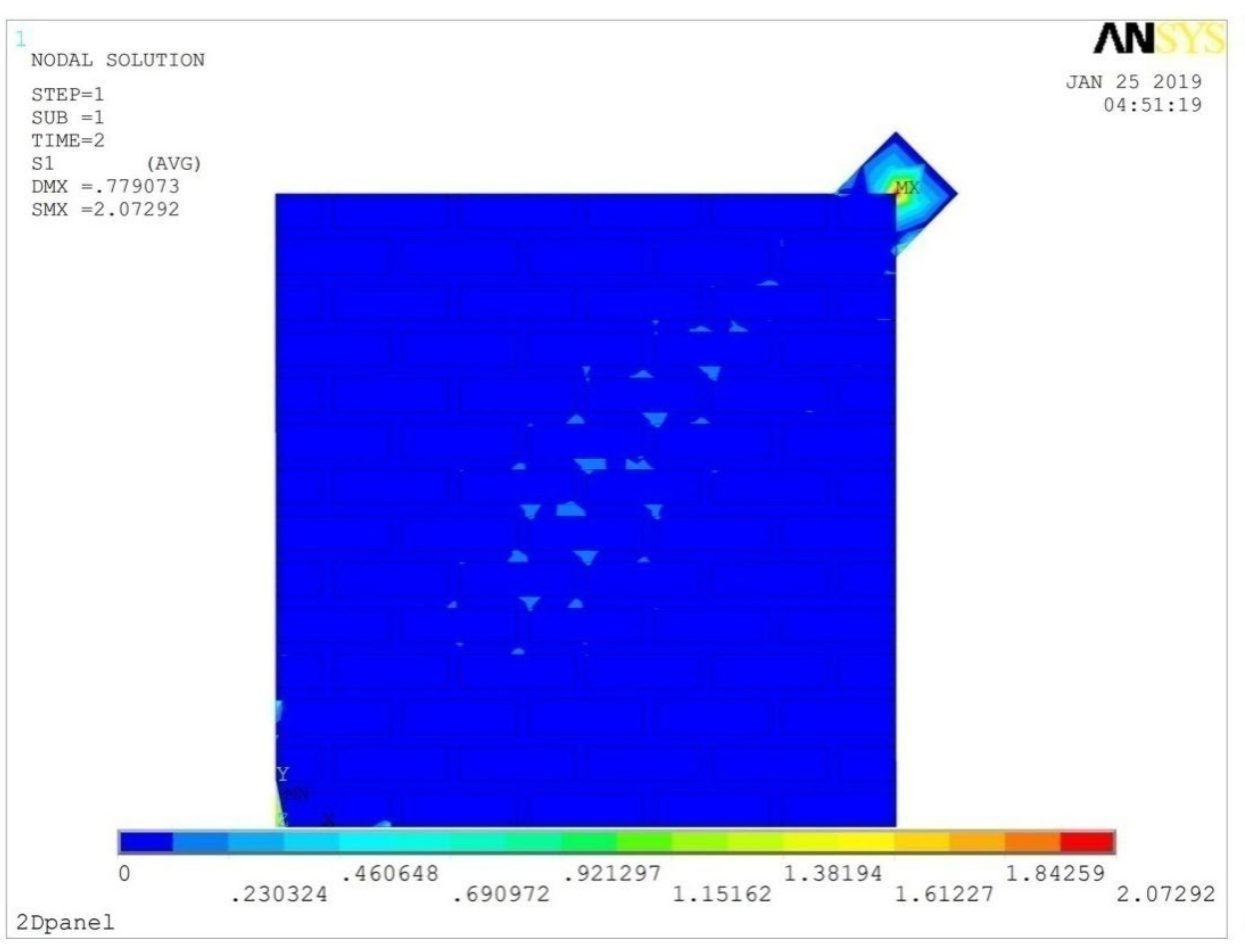

(c)

Fig. 14 (c) Principal tensile stress distribution of unreinforced panel

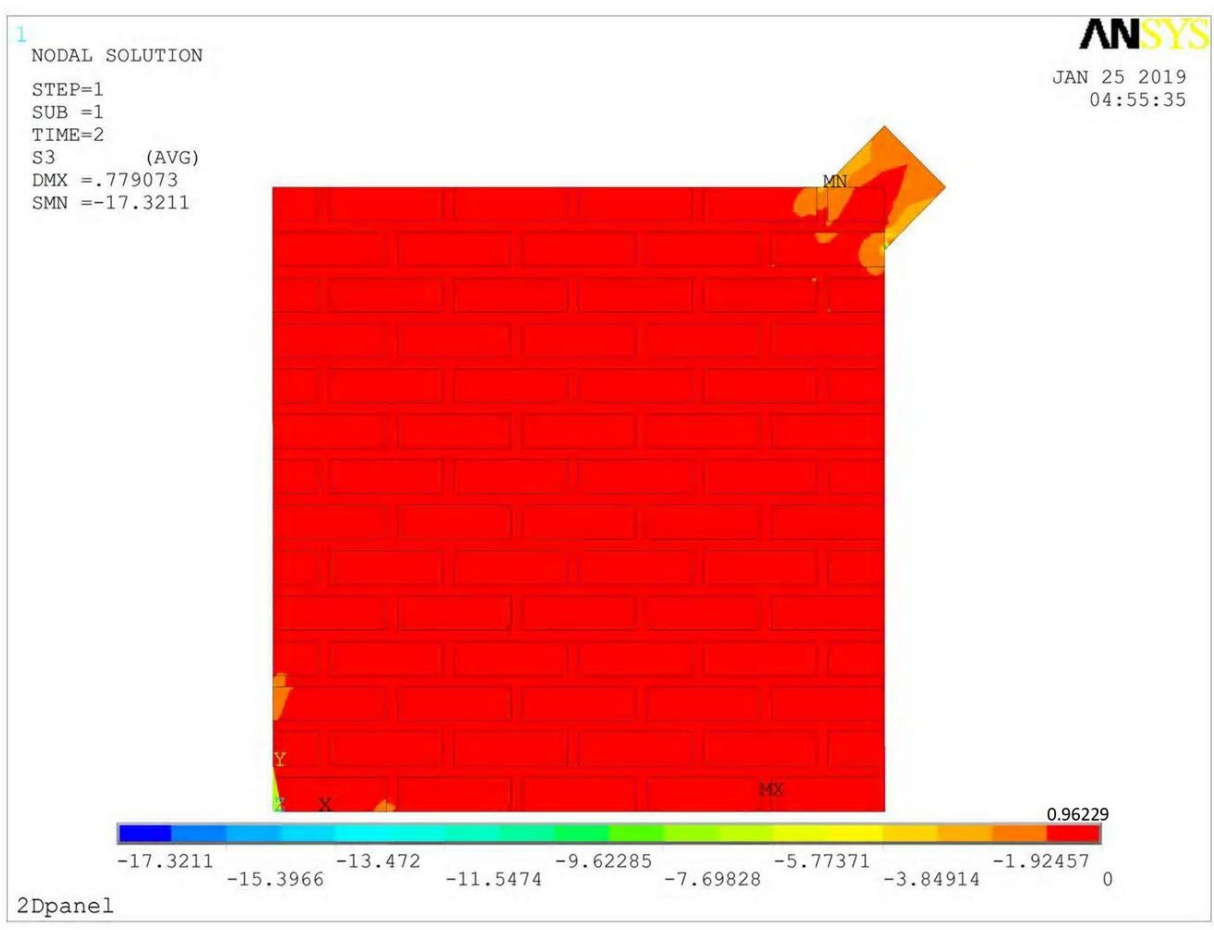

(d)

(d) Principal compressive stress distribution of unreinforced panel 


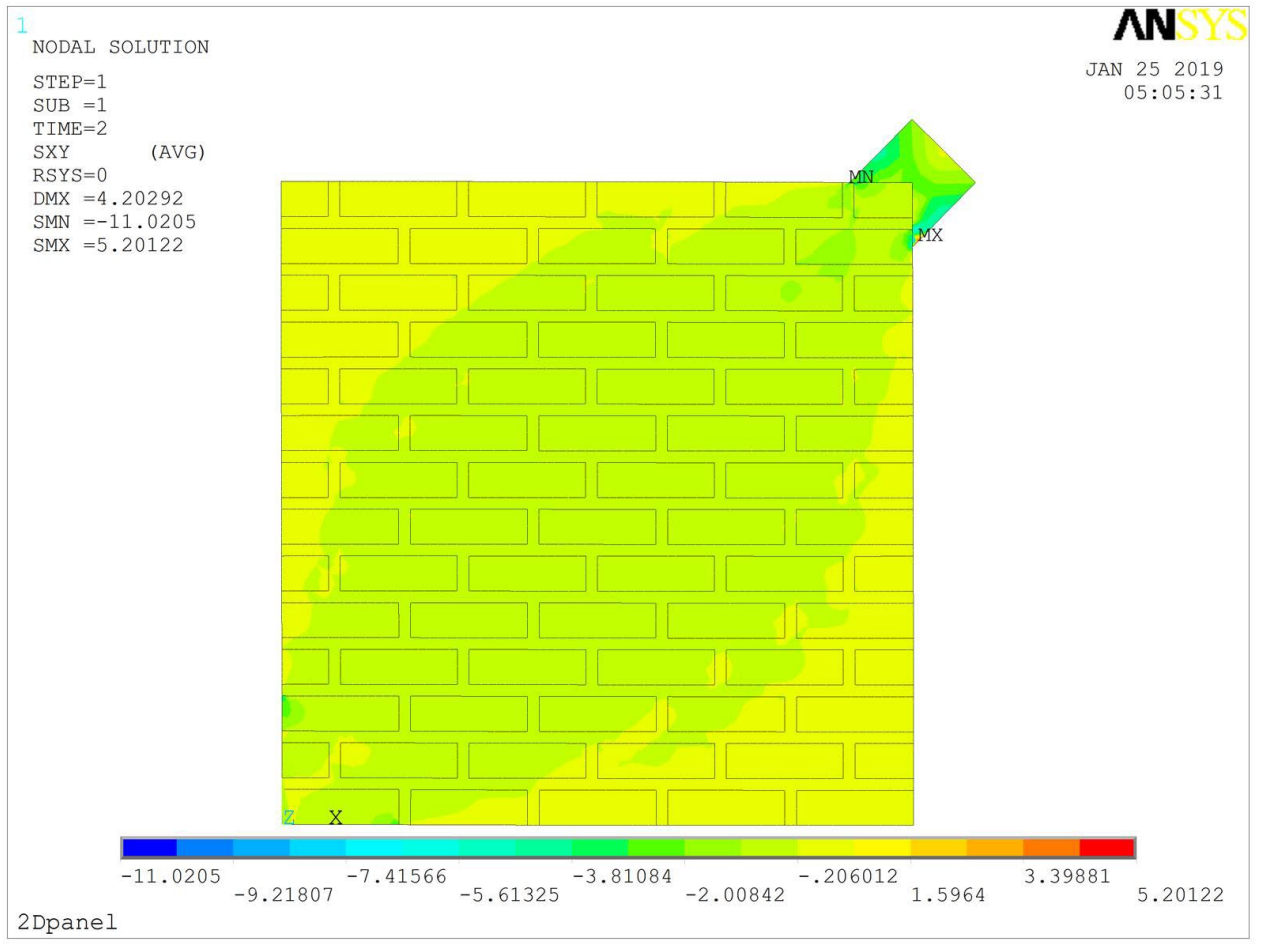

(a)

Fig. 15(a) Shear stress distribution of reinforced panel

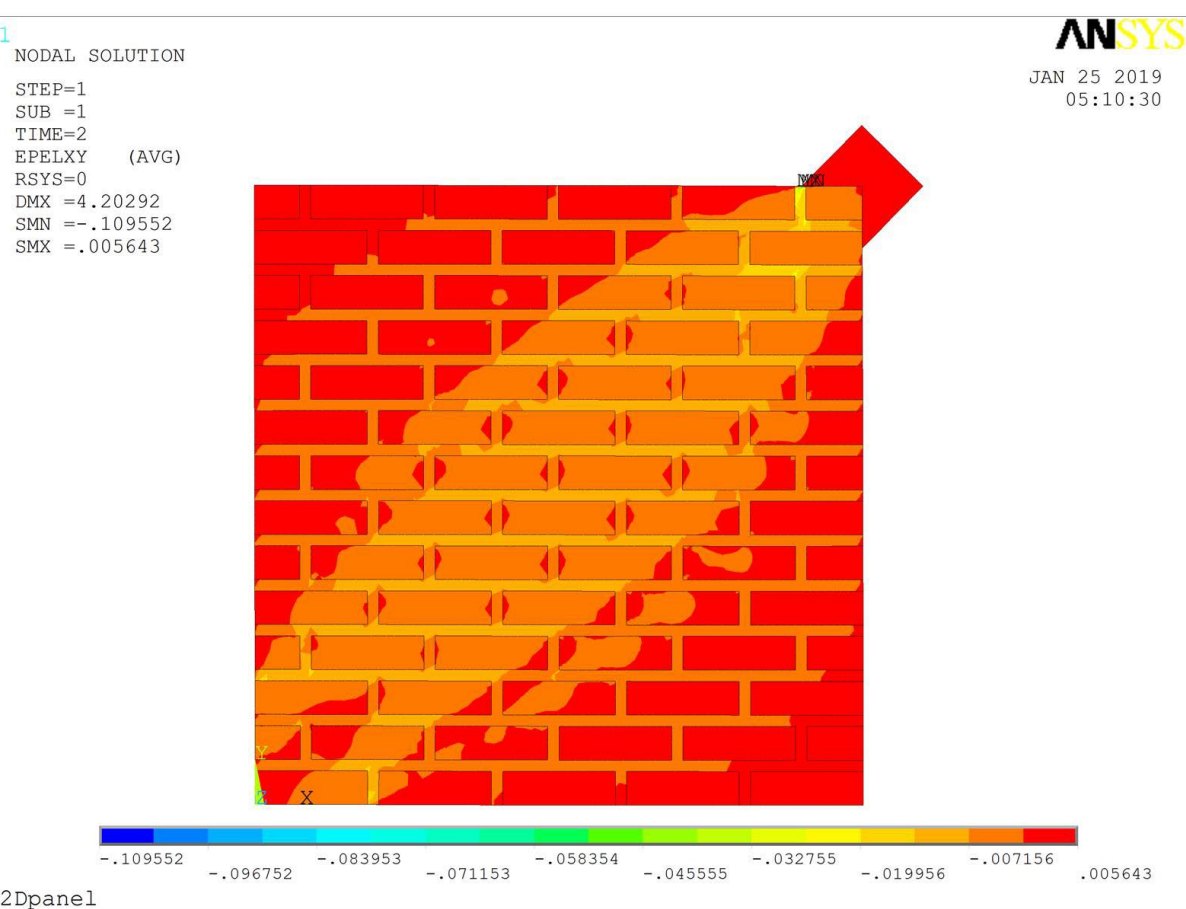

2Dpane

(b)

(b) Shear strain distribution of reinforced panel 


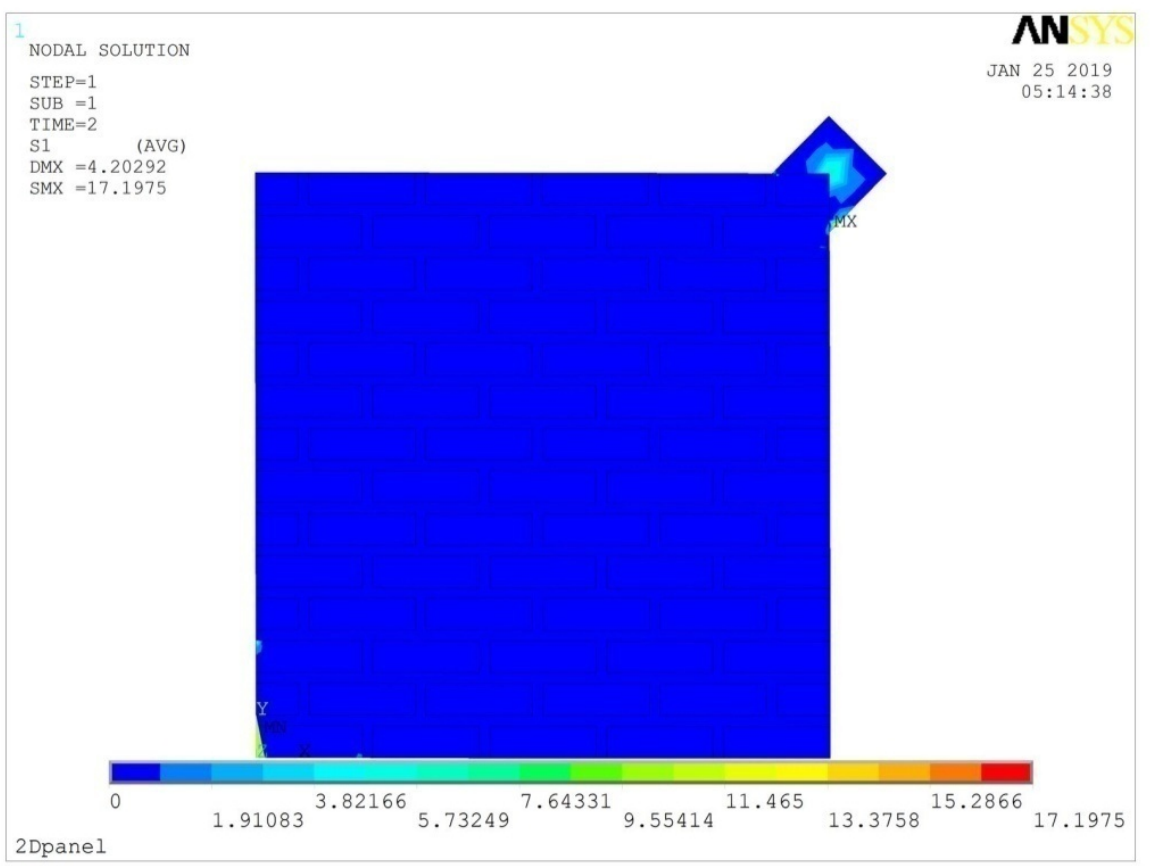

(c)

Fig. 15 (c) Principal tensile stress distribution of reinforced panel

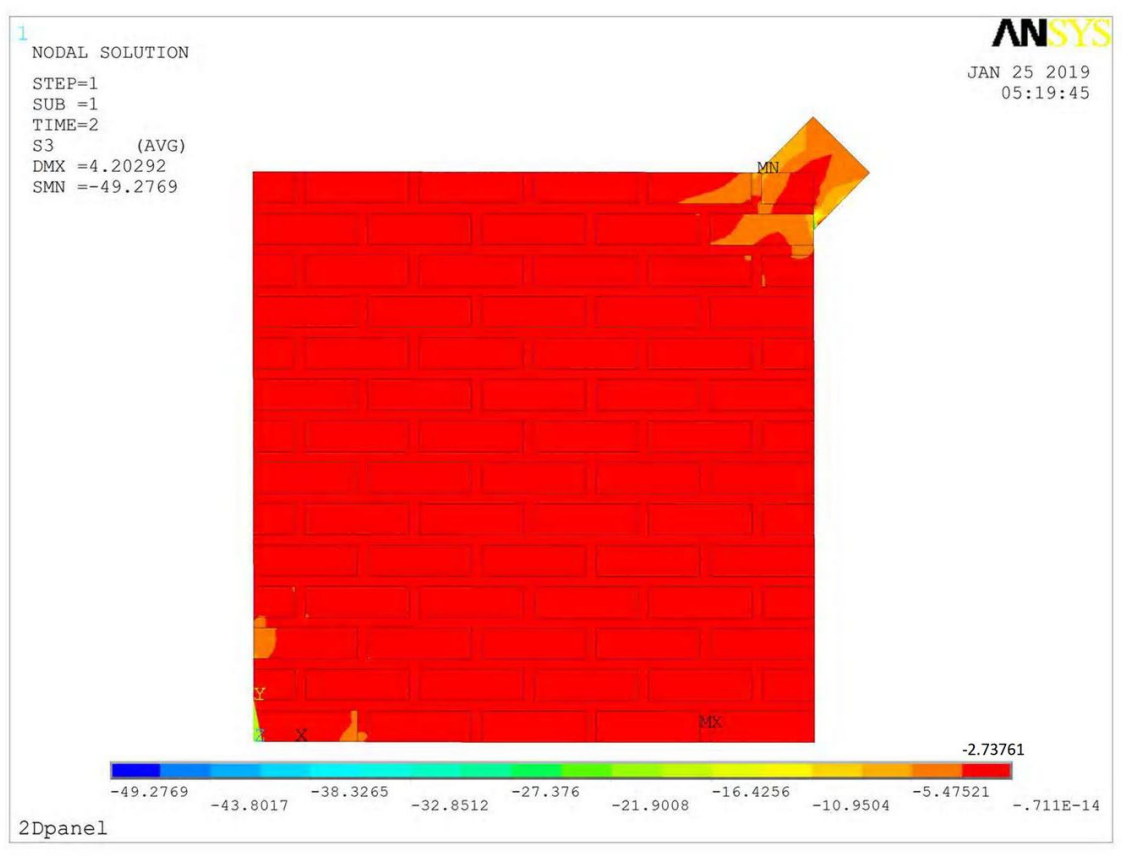

(d)

(d) Principal compressive stress distribution of reinforced panel 
The finite element results show that the stress and strain are high in the direction inclined at $45^{\circ}$ to the horizontal plane of the panel. The normalised principal tensile stresses of about 0.6 and 0.99 for unreinforced and reinforced panels respectively, are indicated. The normalised principal compressive stresses of about 0.96 and 2.7 for unreinforced and reinforced panels respectively, are shown. The corresponding maximum normalised shear stresses of 0.7 and 1.7 for unreinforced and reinforced panels respectively are determined. In the standard interpretation of the masonry diagonal compression test, as provided by ASTM, it is assumed that the stress state at the centre of the panel is of pure shear such that principal tensile stress is equal to shear stress and can be calculated by Eq. 2, and the principal directions coincide with the two diagonals of the panels[15, 21, 28]. According to RILEM, masonry is assumed as an isotropic and homogeneous material such that stress state at the centre of the specimen is not a pure shear state, although the principal directions still coincide with the two diagonals of the panels $[15,16$, 28]. This interpretation gives the values of the principal stress state localised at the centre of the panel given by Eq. 4 and Eq. 5 .

$$
\begin{gathered}
\sigma_{1}=0.5 \frac{P_{u l t}}{A} \\
\sigma_{3}=1.62 \frac{P_{u l t}}{A}
\end{gathered}
$$

where $P_{u l t}$ is the ultimate load and $A$ is the net area of the panel.

The Mohr circles according to ASTM and RILEM interpretations and the stress state of the simulated reinforced and unreinforced panels are shown in Fig. 16. 

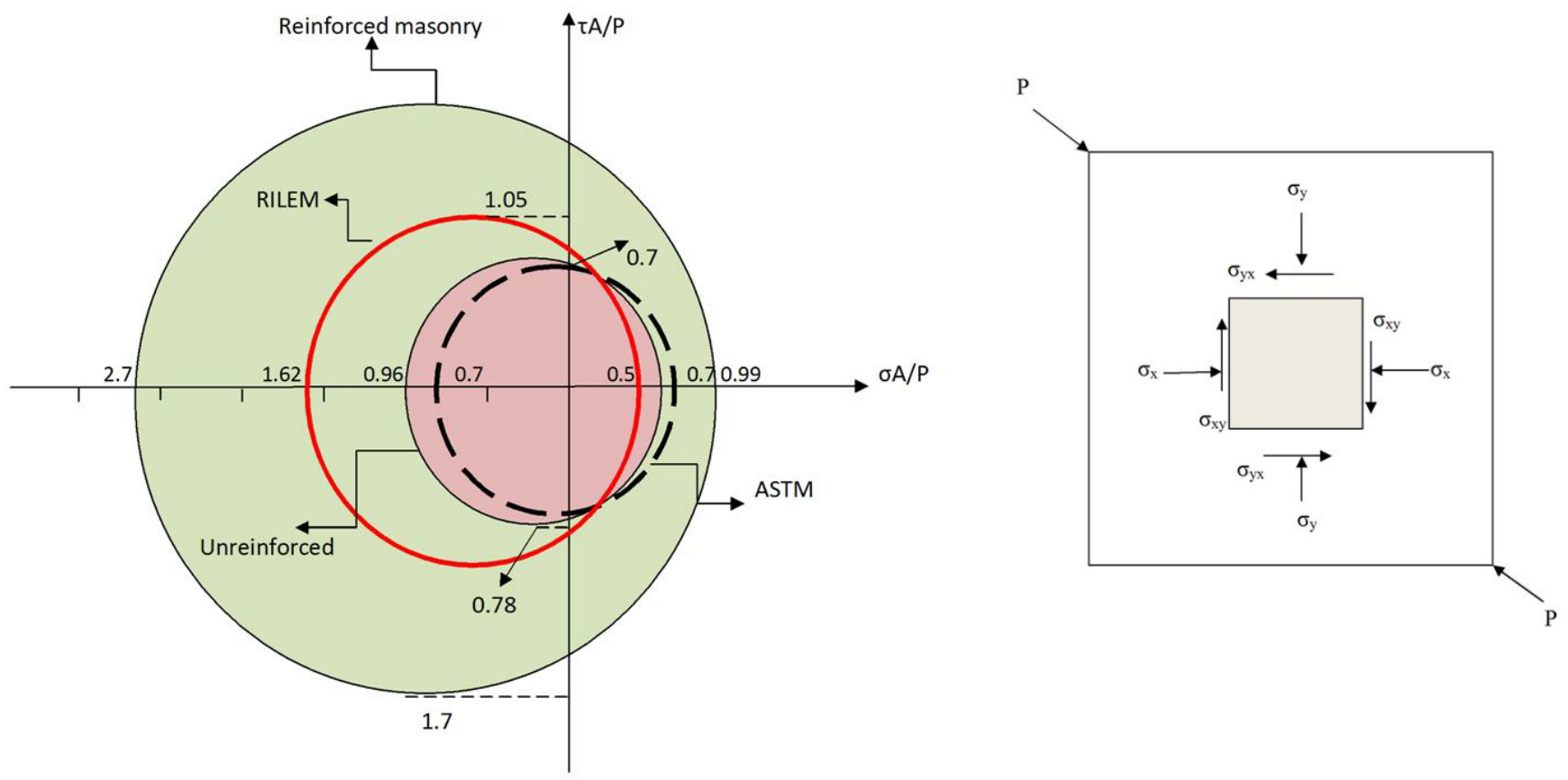

Fig. 16 Normalised Mohr Circles of failure criteria and stress state at the center of the wall panel

It can be seen that the numerical analysis results of the reinforced panel agree with RILEM, irrespective of the stress values. The stress state of the unreinforced panel shows slight deviation from the ASTM assumption. It can be concluded that the stress state at the center of the panel for both panels is not a pure shear state and can better be described by RILEM interpretation.

\section{Design of vertically and laterally loaded adobe masonry wall}

The typical maximum dimensions of adobe houses in the developing countries are $8 \times 5 \times 2.5 \mathrm{~m}[29]$. The typical thickness is double brick wall of about $250 \mathrm{~mm}$.

\subsection{Case 1: Vertical Load resistance}

The design procedure according to BS5628 [30] and Eurocode 6 [13] is adopted. The design 
assumptions and adobe wall specificatons include: wall dimensions of $8 \mathrm{~m}$ length, $2.5 \mathrm{~m}$ height and $0.25 \mathrm{~m}$ thickness, category II of masonry units, normal construction control and material reduction factor of 3 (Table 2.3 of EC6), simple restraint is provided by the roof, load eccentricity at the top of the wall is less than $0.005 \mathrm{t}$ ( $\mathrm{t}$ is the thickness of the wall), the typical slenderness ratio is about 10, typical wall capacity reduction factor is 0.97 (Table 7 BS5628). Vertical load resistance is given by Eq. 6 .

$$
N_{r} \leq \frac{\beta f_{k} t}{\gamma_{m}}
$$

where , $\gamma_{\mathrm{m}}=3, \beta=0.97, f_{k}$ is characteristic masonry compressive strength.

For unreinforced wall, $f_{k}=0.5 \mathrm{MPa}$ (Refer to results of wallet compressive strength), load resistance is $\mathrm{N}_{\mathrm{r}} \leq 40 \mathrm{kN} / \mathrm{m}$ of the wall.

For reinforced wall, $f_{k}=1.3 \mathrm{MPa}$, load resistance is $\mathrm{N}_{\mathrm{r}} \leq 100 \mathrm{kN} / \mathrm{m}$ of the wall.

\subsection{Case 2: Lateral shear resistance}

Using limit state design approach and maximum vertical load resistance $(40 \mathrm{~N} / \mathrm{mm}$ of unreinforced wall and $100 \mathrm{~N} / \mathrm{mm}$ of reinforced wall) and assuming that the wall is fully vertically loaded, allowable shear resistance of the wall is given by Eq. 7 .

$$
F_{r}=N_{r} \tan \varphi
$$

where $\Phi$ is the friction angle determined by triplet test, $32^{\circ}$ and $39^{\circ}$ for unreinforced and reinforced mortar, respectively.

For unreinforced wall, $N_{r}=40 \mathrm{kN} / \mathrm{m}$ of the wall and allowable shear resistance is $F_{r} \leq 25 \mathrm{kN} / \mathrm{m}$ of the wall.

For reinforced wall, $N_{r}=100 \mathrm{kN} / \mathrm{m}$ of the wall and allowable shear resistance is $F_{r} \leq 80 \mathrm{kN} / \mathrm{m}$ of the wall. 


\section{Conclusions}

The mechanical properties of fiber reinforced and unreinforced adobe masonry were investigated by series of laboratory tests namely, masonry triplet, couplets and prisms tests. The shear strength, tensile bond resistance and compressive strength of the masonry elements were determined. Masonry structural performance was assessed by uniaxial compression and diagonal compression shear tests on wallets and wall panels. Finite element linear elastic analysis was performed to evaluate the stress state condition of both loaded reinforced and unreinforced wall panels. Adobe masonry wall was designed according to BS5628 and Eurocode 6 standards by utilising material properties acquired from the experiments. Based on the acquired results, the following conclusions were drawn;

1. Fiber inclusion increased tensile resistance of mortar from $28.2 \mathrm{~N}$ to $37 \mathrm{~N}$, representing $31 \%$ of strength improvement.

2. Fiber inclusion caused an increase in shear strength of adobe masonry from an average value of $0.028 \mathrm{kPa}$ to $0.035 \mathrm{kPa}$ with lateral confinement of $0.025 \mathrm{kPa}$. Shear strength increased from $0.085 \mathrm{kPa}$ to $0.105 \mathrm{kPa}$ with higher lateral confinement of $0.1 \mathrm{kPa}$ and fiber inclusion. The corresponding friction coefficient increased from 0.63 to 0.81 , representing $22 \%$ of improvement.

3. Fiber inclusion in either the mortar or the bricks caused an increase in the compressive strength of the adobe prisms from $0.4 \mathrm{MPa}$ to $0.5 \mathrm{MPa}$, representing $25 \%$ of increase. An average strength of wallets increased from $0.53 \mathrm{MPa}$ to $1.3 \mathrm{MPa}$ with fiber reinforcement in both the mortar and the bricks.

4. The average shear strength of the adobe wall panels increased from $0.014 \mathrm{MPa}$ to 0.047MPa while average shear modulus increased from 9.32 MPa to 41.6MPa with fiber 
inclusion in the mortar.

5. The shear stress state in the reinforced and unreinforced wall panel was not a pure shear state and was better described by RILEM interpretation.

6. Fiber reinforced adobe masonry exhibited ductile behaviour and the failure mode of the unreinforced was brittle.

7. The load resistance of the vertically loaded adobe fiber reinforced masonry wall was estimated as $100 \mathrm{kN} / \mathrm{m}$ of the wall while unreinforced wall could support load of approximately $40 \mathrm{kN} / \mathrm{m}$ of the wall. The shear resistance of reinforced wall was estimated as $80 \mathrm{kN} / \mathrm{m}$ and unreinforced wall could support shear load of about $25 \mathrm{kN} / \mathrm{m}$ of the wall.

\section{Data Availability}

This publication is in compliance with EPSRC Open Access framework. The underlying data to reproduce the experimental curves are provided in Kafodya et al. 2019 [31].

\section{Acknowledgements}

This work was part of the doctoral research funded by Malawi government under Skills Development Project (SDP), Project No. P131660. The experimental part was supported by the UK Global Challenges Research fund through the Engineering and Physical Sciences Research Council under grant no. EP/P028233/1 (PREPARE). Special thanks to the University of Bristol, UK for providing the testing equipment and resources and the University of Malawi, The Polytechnic for providing the laboratory space and facilities 


\section{References}

[1] Houben. $\mathrm{H}$ and Guillaud. H, Earth Construction: A Comprehensive Guide, IT Publications, London, 1994.

[2] Walker. P, Bond Characteristics of earth block masonry, J Mater Civ Eng 11(1999) 249256.

[3] Mesbah et al, Development of a Direct Tensile Test for Compacted Earth Blocks Reinforced with Natural Fibers, J Mater Civ Eng 16(2004) 95-98.

[4] Walker. P, Strength and Erosion Characteristics of Earth Blocks and Earth Block Masonry, J Mater Civ Eng 16(2004) 497-506.

[5] Zami. M S and Le. A, Economic benefits of contemporary earth construction in low-cost urban housing - State-of-the-art review, J Build Appr 5(2010) 259-271.

[6] Islam. M.S and Iwashita . K, Earthquake resistance of adobe reinforced by low cost traditional materials, J Nat Dis Sci 32(2010) 21.

[7] Consoli et al, Parameters controlling tensile and compressive strength of fiber-reinforced cemented soil, J Mater Civ Eng (2012).

[8] Moghal et al, , Effect of polypropylene fibre reinforcement on the consolidation, swell and shrinkage behaviour of lime-blended expansive soil, Int J Geotech Eng 12 (2018) 462-471.

[9] Binici et al, Investigation of fibre reinforced mud brick as a building materia, Constr and Build Mater 19(2005) 313-318.

[10] Sharma et al, Enhancing sustainability of rural adobe houses of hills by addition of vernacular fiber reinforcement, Inte J of Sustain Built Environ 4(2015) 348-358.

[11] Blondet et al, Earthquake resistant of earthen construction: The great contemporary experience of Pontifical Catholic University of Peru., Inf Constr 63(2011) 41-50

[12] Figueiredo et al, Seismic retrofitting solution of an adobe masonry wall, Mater. Struct. 46(2013) 203-219.

[13] ENV 1992-2, Design of masonry structures, CEN, 2006.

[14] Novelli et al, Seismic Mitigation Framework for Non-engineered Masonry Buildings in Developing Countries: Application to Malawi in the East African Rift, Resilient Structures and Infrastructure, Springer, Singapore, 2019

[15] Alecci et al, Shear strength of brick masonry walls assembled with different types of mortar, Constr Build Mater 40(2013) 1038-1045. 
[16] RILEM LUMB6, Diagonal tensile strength tests of small wall specimens 1991, Rilem recommendations for the testing and use of constructions materials, RILEM, London, 1994, pp. 488-489.

[17] ASTM C67-03a, Standard test methods for sampling and testing bricks an clay tiles, ASTM, Conshohocken PA, 2003.

[18] BS EN 1015-11, Methods of test for mortar for masonry. Determination of flexural and compressive strength of hardened mortar, BIS, 1999.

[19] ASTM C1314-03b, Standard test method for compressive strength of masonry prisms ASTM, Conshohocken PA, 2003.

[20] BS EN 1052-3, Method of test for masonry: Determination of initial shear strength, BSI, 2002.

[21] ASTME519-15, Standard test method for diagonal tension (shear), in masonry assemblages, ASTM, Conshohocken PA, 2015.

[22] Vicente. EF and Torrealva. DE, Mechanical Properties of adobe masonry of historical buildings in Peru, in: F.P.a.M. Chávez, (Ed), 9th In Conf Structl Anal Histl Constr Mexico City, Mexico 2014.

[23] Nazeer et al, Behaviour and strength assessment of masonry prisms, Case Stud Constr Mater 8(2018) 23-38.

[24] Feng Wu , Hong-Nan Li , Jin-Qing Jia, Strength and stress-strain characteristics of traditional adobe block and masonry, Mater Struct 46(2013) 1449-1457.

[25] Tetley. R and Madabhushi. G, Vulnerability of adobe buildings under earthquake loading, 4th International Conference of Earthquake Geotechnical Engineering Paper No 1244, Thessaloniki- Greece, 2007

[26] Varum et al, Mechanical Characterization of Adobe Masonry Walls in: L.R.a.A.B. Rivera, (Ed), Terra 2008: The 10th International Conference on the Study and Conservation of earthen archtectural heritage, Getty Conservation institute and Mali minstry of culture, Bamako Mali, 2008, pp. 307-311

[27] Gabor et al, Modelling approaches of the in-plane shear behaviour of unreinforced and FRP strengthened masonry panels, Compos Struct 74(2006) 277-288.

[28] Brignola et al, Identification of shear parameters of masonry panels through the in situ diagonal compression test, Int J Archit Heritage 3(2009) 52-73.

[29] Novelli et al, A Resource on construction in Earthquake Regions, The World Housing Encyclopedia EERI and IAEE, 2018.

[30] BS 5628-1, Code of practice for structural use of unreinforced masonry, BSI, London, 
2005.

[31] Kafodya, I., Okonta, F., and Kloukinas P. (2019) Supporting Data for 'Role of fiber inclusion in adobe masonry construction'. University of Bristol data repository. 2019. [accessed 02 August 2019] 